\title{
Home-based versus clinic-based specimen collection in the management of Chlamydia trachomatis and Neisseria gonorrhoeae infections (Review)
}

Fajardo-Bernal L, Aponte-Gonzalez J, Vigil P, Angel-Müller E, Rincon C, Gaitán HG, Low N

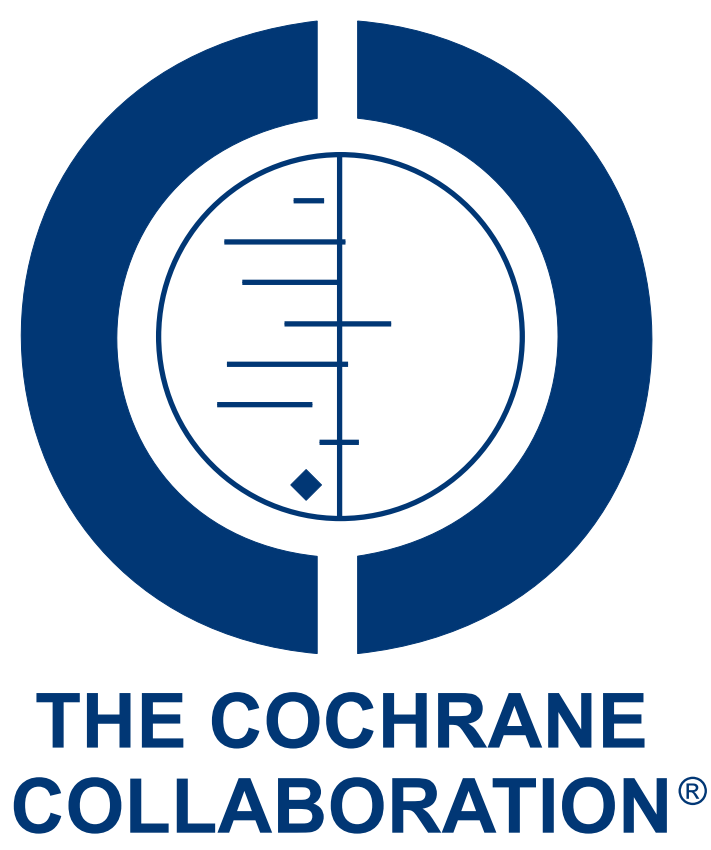

This is a reprint of a Cochrane review, prepared and maintained by The Cochrane Collaboration and published in The Cochrane Library 2015, Issue 9

http://www.thecochranelibrary.com

\section{WILEY}

Home-based versus clinic-based specimen collection in the management of Chlamydia trachomatis and Neisseria gonorrhoeae infections (Review)

Copyright $\odot 2015$ The Cochrane Collaboration. Published by John Wiley \& Sons, Ltd. 
TABLE OF CONTENTS

HEADER

ABSTRACT

PLAIN LANGUAGE SUMMARY

OBJECTIVES

METHODS . . .

RESULTS . . . . . . . . . . . . . . . . . . . . . . . . . . . . . . . . 12

Figure 1. . . . . . . . . . . . . . . . . . . . . . . . . . . . . . . . . . . . . 13

Figure 2. . . . . . . . . . . . . . . . . . . . . . . . . . . . . . . . . . . . . . 16

Figure 3. . . . . . . . . . . . . . . . . . . . . . . . . . . . . . . . . . . . . . 17

Figure $4 . \quad$. . . . . . . . . . . . . . . . . . . . . . . . . . . . . . . . . . . . . 19

Figure 5. . . . . . . . . . . . . . . . . . . . . . . . . . . . . . . . . . . . . . 20

Figure 6. . . . . . . . . . . . . . . . . . . . . . . . . . . . . . . . . . . . . . 21

DISCUSSION . . . . . . . . . . . . . . . . . . . . . . . . . . . . . . . . . . . . . .

AUTHORS' CONCLUSIONS . . . . . . . . . . . . . . . . . . . . . . . . . . . . . . . . 23

ACKNOWLEDGEMENTS . . . . . . . . . . . . . . . . . . . . . . . . . . . . . . . . . 23

REFERENCES . . . . . . . . . . . . . . . . . . . . . . . . . . . . . . . . . . . . . . 24

CHARACTERISTICS OF STUDIES . . . . . . . . . . . . . . . . . . . . . . . . . . . . . . . . . . . . . . .

DATA AND ANALYSES . . . . . . . . . . . . . . . . . . . . . . . . . . . . . . . . . . . . . . . . . . . . . . . . . . . .

Analysis 1.1. Comparison 1 Home-based vs clinic-based specimen collection for CT and NG, Outcome 1 Index Case Management.

Analysis 1.2. Comparison 1 Home-based vs clinic-based specimen collection for CT and NG, Outcome 2 Proportion of individuals tested.

Analysis 1.3. Comparison 1 Home-based vs clinic-based specimen collection for CT and NG, Outcome 3 Proportion of individual tested grouped by sex.

Analysis 1.4. Comparison 1 Home-based vs clinic-based specimen collection for CT and NG, Outcome 4 Proportion of individual tested grouped by risk.

Analysis 1.5. Comparison 1 Home-based vs clinic-based specimen collection for CT and NG, Outcome 5 Proportion of individual tested grouped by method of returning specimens.

Analysis 1.6. Comparison 1 Home-based vs clinic-based specimen collection for CT and NG, Outcome 6 Proportion of individual tested grouped by use of reminders.

Analysis 1.7. Comparison 1 Home-based vs clinic-based specimen collection for CT and NG, Outcome 7 Positive test prevalence. . . . . . . . . . . . . . . . . . . . . . . . . . . . . . . . . . . . 55

ADDITIONAL TABLES . . . . . . . . . . . . . . . . . . . . . . . . . . . . . . . . . . . . .

APPENDICES . . . . . . . . . . . . . . . . . . . . . . . . . . . . . . . . . 56

CONTRIBUTIONS OF AUTHORS . . . . . . . . . . . . . . . . . . . . . . . . . . . . . . . . . . . . . 59

DECLARATIONS OF INTEREST . . . . . . . . . . . . . . . . . . . . . . . . . . . . . . . . 60

SOURCES OF SUPPORT . . . . . . . . . . . . . . . . . . . . . . . . . . . . . . . . . . . . . . . . . 60

DIFFERENCES BETWEEN PROTOCOL AND REVIEW . . . . . . . . . . . . . . . . . . . . . . . . . . . . 60

Home-based versus clinic-based specimen collection in the management of Chlamydia trachomatis and Neisseria gonorrhoeae 


\title{
Home-based versus clinic-based specimen collection in the management of Chlamydia trachomatis and Neisseria gonorrhoeae infections
}

\author{
Luisa Fajardo-Bernal ${ }^{1}$, Johanna Aponte-Gonzalez ${ }^{1}$, Patrick Vigil ${ }^{2}$, Edith Angel-Müller ${ }^{3}$, Carlos Rincon ${ }^{4}$, Hernando G Gaitán ${ }^{1,3}$, \\ Nicola Low 5 \\ ${ }^{1}$ Clinical Research Institute, Faculty of Medicine, Universidad Nacional de Colombia, Bogota, Colombia. ${ }^{2}$ Central Washington Family \\ Medicine, Yakima, Washington, USA. ${ }^{3}$ Department of Obstetrics and Gynecology, Faculty of Medicine, Universidad Nacional de \\ Colombia, Bogota, Colombia. ${ }^{4}$ Department of Clinical Epidemiology and Biostatistics, Pontificia Universidad Javeriana, Bogotá, \\ Colombia. ${ }^{5}$ Institute of Social and Preventive Medicine (ISPM), University of Bern, Bern, Switzerland \\ Contact address: Luisa Fajardo-Bernal, Clinical Research Institute, Faculty of Medicine, Universidad Nacional de Colombia, KR 30
} 45 03, Bogota, Colombia.1mfajardob@unal.edu.co.

Editorial group: Cochrane Sexually Transmitted Infections Group.

Publication status and date: New, published in Issue 9, 2015.

Review content assessed as up-to-date: 27 May 2015.

Citation: Fajardo-Bernal L, Aponte-Gonzalez J, Vigil P, Angel-Müller E, Rincon C, Gaitán HG, Low N. Home-based versus clinicbased specimen collection in the management of Chlamydia trachomatis and Neisseria gonorrhoeae infections. Cochrane Database of Systematic Reviews 2015, Issue 9. Art. No.: CD011317. DOI: 10.1002/14651858.CD011317.pub2.

Copyright (C 2015 The Cochrane Collaboration. Published by John Wiley \& Sons, Ltd.

\begin{abstract}
A B S T R A C T
Background

Chlamydia trachomatis (CT) and Neisseria gonorrhoeae (NG) are the most frequent causes of bacterial sexually transmitted infections (STIs). Management strategies that reduce losses in the clinical pathway from infection to cure might improve STI control and reduce complications resulting from lack of, or inadequate, treatment.
\end{abstract}

Objectives

To assess the effectiveness and safety of home-based specimen collection as part of the management strategy for Chlamydia trachomatis and Neisseria gonorrhoeae infections compared with clinic-based specimen collection in sexually-active people.

Search methods

We searched the Cochrane Sexually Transmitted Infections Group Specialized Register, the Cochrane Central Register of Controlled Trials (CENTRAL), MEDLINE, EMBASE and LILACS on 27 May 2015, together with the World Health Organization International Clinical Trials Registry (ICTRP) and ClinicalTrials.gov. We also handsearched conference proceedings, contacted trial authors and reviewed the reference lists of retrieved studies.

\section{Selection criteria}

Randomized controlled trials (RCTs) of home-based compared with clinic-based specimen collection in the management of $C$. trachomatis and N. gonorrhoeae infections.

Home-based versus clinic-based specimen collection in the management of Chlamydia trachomatis and Neisseria gonorrhoeae infections (Review)

Copyright $\odot 2015$ The Cochrane Collaboration. Published by John Wiley \& Sons, Ltd. 


\section{Data collection and analysis}

Three review authors independently assessed trials for inclusion, extracted data and assessed risk of bias. We contacted study authors for additional information. We resolved any disagreements through consensus. We used standard methodological procedures recommended by Cochrane. The primary outcome was index case management, defined as the number of participants tested, diagnosed and treated, if test positive.

\section{Main results}

Ten trials involving 10,479 participants were included. There was inconclusive evidence of an effect on the proportion of participants with index case management (defined as individuals tested, diagnosed and treated for CT or NG, or both) in the group with homebased $(45 / 778,5.8 \%)$ compared with clinic-based $(51 / 788,6.5 \%)$ specimen collection (risk ratio (RR) 0.88 , 95\% confidence interval (CI) 0.60 to $1.29 ; 3$ trials, $\mathrm{I}^{2}=0 \%, 1566$ participants, moderate quality). Harms of home-based specimen collection were not evaluated in any trial. All 10 trials compared the proportions of individuals tested. The results for the proportion of participants completing testing had high heterogeneity $\left(\mathrm{I}^{2}=100 \%\right)$ and were not pooled. We could not combine data from individual studies looking at the number of participants tested because the proportions varied widely across the studies, ranging from 30\% to $96 \%$ in home group and $6 \%$ to $97 \%$ in clinic group (low-quality evidence). The number of participants with positive test was lower in the home-based specimen collection group $(240 / 2074,11.6 \%)$ compared with the clinic-based group (179/967, 18.5\%) (RR 0.72, $95 \%$ CI 0.61 to 0.86 ; 9 trials, $\mathrm{I}^{2}=0 \%, 3041$ participants, moderate quality).

\section{Authors' conclusions}

Home-based specimen collection could result in similar levels of index case management for CT or NG infection when compared with clinic-based specimen collection. Increases in the proportion of individuals tested as a result of home-based, compared with clinic-based, specimen collection are offset by a lower proportion of positive results. The harms of home-based specimen collection compared with clinic-based specimen collection have not been evaluated. Future RCTs to assess the effectiveness of home-based specimen collection should be designed to measure biological outcomes of STI case management, such as proportion of participants with negative tests for the relevant STI at follow-up.

\section{PLAIN LANGUAGE SUMMARY}

\section{Home-based specimen collection in the management of chlamydia and gonorrhoea infections}

Review question: Cochrane authors reviewed evidence about the effects of self-collected specimens at home compared with specimens collected at clinic on the clinical management of chlamydia and gonorrhoea infections.

Background: Chlamydia and gonorrhoea are common sexually transmitted infections (STI). Management of these infections might be easier to achieve if people can collect specimens at home and send or take them to a laboratory, rather than having to go to a clinic.

Search date: This evidence is up to May 2015.

Study characteristics: We searched the available literature for trials in which people were invited either to collect specimens at home or to attend a clinic for collection of specimens. We found 10 relevant trials in total. Three trials (including 1566 people) provided data to assess the proportion of people who completed testing, diagnosis and treatment. All trials gave information about the percentages of people who took self-collected specimens for detection of chlamydia and gonorrhoea infections at home and those who took the test at a clinic. Nine studies reported percentages related to positive test results.

Funding sources: Trials in this review were funded by governmental or non-governmental organisations.

Key results: There was no evidence of a difference between home-based and clinic-based specimen collection in the proportion of people who completed testing, diagnosis and treatment. In the home-based group 45 infections were detected and treated in a total of 778 people invited to collect specimens at home. In the clinic-based group 51 infections were detected and treated in a total of 788 people invited to attend a clinic. We could not combine data from individual studies looking at the number of participants tested because the proportions varied widely. A lower number of participants diagnosed in the home-based compared with the clinic-based group was documented. The potential harms of testing with home-collected specimens were not evaluated in any trial.

Quality of the evidence: The GRADE quality for the main outcomes was moderate (index case management, positive test prevalence) or low (proportion of individuals tested). The quality of evidence was downgraded because of methodological limitations in the studies.

Home-based versus clinic-based specimen collection in the management of Chlamydia trachomatis and Neisseria gonorrhoeae 
Conclusions: Home-based specimen collection could result in similar levels of index case management for Chlamydia trachomatis or Neisseria gonorrhoeae infection when compared with clinic-based specimen collection. The safety of home-based specimen collection compared with clinic-based specimen collection have not been evaluated. 
SUMMARY OF FINDINGS FOR THE MAIN COMPARISON [Explanation]

Home-based compared with clinic-based specimen collection for Chlamydia trachomatis and Neisseria gonorrhoeae

Patient or population: Sexually active people

Setting: Outpatient

Intervention: Home-based specimen collection

Comparison: Clinic-based specimen collection

\begin{tabular}{|c|c|c|c|c|c|c|}
\hline \multirow[t]{2}{*}{ Outcomes } & \multicolumn{2}{|c|}{ Anticipated absolute effects* (95\% Cl) } & \multirow{2}{*}{$\begin{array}{l}\text { Relative effect } \\
(95 \% \text { Cl) }\end{array}$} & \multirow{2}{*}{$\begin{array}{l}\text { № of participants } \\
\text { (studies) }\end{array}$} & \multirow{2}{*}{$\begin{array}{l}\text { Quality of the evidence } \\
\text { (GRADE) }\end{array}$} & \multirow[t]{2}{*}{ Comments } \\
\hline & \multicolumn{2}{|c|}{$\begin{array}{l}\text { Risk with clinic-based Risk with Home-based } \\
\text { specimen collection for } \\
\text { CT and NG }\end{array}$} & & & & \\
\hline \multirow{4}{*}{$\begin{array}{l}\text { Index case management } \\
\text { ( } 6 \text { to } 12 \text { weeks of follow- } \\
\text { up) }\end{array}$} & \multicolumn{2}{|c|}{ Study population } & \multirow{4}{*}{$\begin{array}{l}\text { RR } 0.88 \\
(0.60 \text { to } 1.29)\end{array}$} & \multirow{4}{*}{$\begin{array}{l}1566 \\
\text { (3 RCTs) }\end{array}$} & \multirow{4}{*}{ MODERATE ${ }^{1}$} & \\
\hline & 65 per 1000 & $\begin{array}{l}57 \text { per } 1000 \\
\text { (39 to } 83)\end{array}$ & & & & \\
\hline & \multicolumn{2}{|l|}{ Moderate } & & & & \\
\hline & 105 per 1000 & $\begin{array}{l}93 \text { per } 1000 \\
(63 \text { to } 136)\end{array}$ & & & & \\
\hline $\begin{array}{l}\text { Proportion of individuals } \\
\text { tested } \\
\text { (12 days to } 8 \text { weeks of } \\
\left.\text { follow-up }{ }^{a}\right)\end{array}$ & \multicolumn{2}{|c|}{$\begin{array}{l}\text { Eight of the ten trials found that home-based spec- } \\
\text { imen collection resulted in more participants being } \\
\text { tested than clinic-based specimen collection }\end{array}$} & Not pooled ${ }^{b}$ & $\begin{array}{l}10479 \\
\text { (10 RCTs) }\end{array}$ & $\mathrm{LOW}^{2}$ & \\
\hline \multirow[t]{3}{*}{ Positive test prevalence } & \multicolumn{2}{|c|}{ Study population } & \multirow{3}{*}{$\begin{array}{l}\text { RR } 0.72 \\
(0.61 \text { to } 0.86)\end{array}$} & \multirow{3}{*}{$\begin{array}{l}3041 \\
\text { (9 RCTs) }\end{array}$} & \multirow{3}{*}{ MODERATE ${ }^{1}$} & \\
\hline & 185 per 1000 & $\begin{array}{l}133 \text { per } 1000 \\
(113 \text { to } 159)\end{array}$ & & & & \\
\hline & Moderate & & & & & \\
\hline
\end{tabular}


*The risk in the intervention group (and its $95 \%$ confidence interval) is based on the assumed risk in the comparison group and the relative effect of the intervention (and its $95 \% \mathrm{Cl}$ ).

Cl: Confidence interval; RR: Risk ratio; OR: Odds ratio;

\section{GRADE Working Group grades of evidence}

High quality: We are very confident that the true effect lies close to that of the estimate of the effect

Moderate quality: We are moderately confident in the effect estimate: The true effect is likely to be close to the estimate of the effect, but there is a possibility that it is substantially different

Low quality: Our confidence in the effect estimate is limited: The true effect may be substantially different from the estimate of the effect

Very low quality: We have very little confidence in the effect estimate: The true effect is likely to be substantially different from the estimate of effect

${ }^{a}$ One study included follow-up until 2 years

Due to substantial heterogeneity $\left(I^{2}=100 \%\right)$

"No trials reported adverse effects of testing

'Downgraded one level due to serious risk of bias (concerns about blinding and attrition rate $>20 \%$ in two studies)

2Downgraded two levels due to very serious risk of bias (all the trials had a high or unclear risk of bias in at least one key domain i.e.

random sequence generation, allocation concealment and blinding) 


\section{B A C K G R O U N D}

\section{Description of the condition}

Sexually transmitted infections (STIs) are defined as "infections that are spread primarily through person-to-person sexual contact" (WHO 2004). In 2008, the World Health Organization estimated that there were 499 million new cases of syphilis, gonorrhoea, chlamydia and trichomoniasis in sexually-active adults around the world (WHO 2012). Although these are curable STIs, they are still a public health problem, especially in low-income countries where complaints about ulcerative diseases, genital symptoms such as vaginal or urethral secretions, and acute and chronic complications and sequelae of STIs are some of the main problems for which adults seek health care. This implies high costs, not only in terms of productivity by the loss of work days, but also for acute treatment and lengthy management of the complications of STIs (Mayaud 2004).

Chlamydia trachomatis (CT) and Neisseria gonorrhoeae (NG) are the most frequent causes of bacterial STIs (Workowski 2010). Repeated infections cause complications and sequelae manifested as pelvic inflammatory disease (PID), ectopic pregnancy, chronic pelvic pain, and infertility (Carey 2010). Annual costs of treatment for CT and NG infection and their sequelae exceed USD 2.5 billion in the United States of America (USA), of which management of PID is the largest component. The direct cost of cases of CT and NG in women is estimated at USD 315 and USD 343 respectively, and in men USD 26 and USD 68; for PID the direct cost is USD 1925. Indirect costs, such as productivity losses per PID case, are estimated at USD 649 (Mehta 2002; Blandford 2006; Chesson 2008)

CT and NG infection management requires measures at several levels to achieve disease control and reduce complications resulting from lack of treatment or inadequate treatment. Strategies aiming to control the transmission of CT and NG could break the epidemiological chain of infection, which would in turn make related complications easier to treat because they would be less severe (Low 2006). The aim of early diagnosis of CT and NG infections is to reduce the burden of STIs, as these infections are often asymptomatic and affect both index patients and their partners (Low 2006). At the individual level, strengthening the clinical care of patients with curable STI focuses on case management. Comprehensive case management requires correct diagnosis, adequate antibiotic treatment, establishment of prevention measures, and notification and treatment of sexual partners (UNAIDS 1999; WHO 2004; WHO 2005).

Many countries recommend testing for CT and NG to achieve early diagnosis and timely treatment of infected individuals. For example, the Centers for Disease Control and Prevention and the US Preventive Services Task Force have recommended annual CT screening for all sexually-active women aged 25 years or younger (including pregnant women) and for sexually-active women older than 25 years with risk factors, as well as annual gonorrhoea screening for at-risk sexually-active women (USPSTF 2007; Meyers 2008). The effectiveness of strategies to increase testing uptake in reducing the population prevalence of these infections has not been established (Manhart 2005; Low 2006; Low 2007). There are many challenges to implementing such population-level programs because substantial numbers of people are lost at each step in the pathway between infection, treatment seeking, diagnosis, treatment, cure, and avoidance of re-infection (UNAIDS 1999). STI case management usually starts with the patient attending clinical healthcare settings for diagnosis and treatment. There are several challenges to providing effective care in the clinical setting. Where laboratory testing is available, clinical samples are often taken by a healthcare professional and sent to a laboratory; otherwise the patient needs to go to another clinic/laboratory to have samples taken. Thus the patient needs to make at least one extra visit before they receive their results and treatment, if indicated. Nucleic acid amplification tests (NAATs) are now the most widelyused diagnostic tests for CT and NG in many countries. Their sensitivity ranges from $90 \%$ to $100 \%$, and specificity is about $99 \%$ (Gaydos 2004; Masek 2009), but these tests are expensive. Conventional testing in women requires a pelvic examination, speculum use, and urethral, cervical or vaginal swabs. These procedures can be uncomfortable and may constitute barriers to testing because of women's anxiety and fear (Hobbs 2008; Shih 2011). These are reasons for which clinic-based case management might result in loss to follow-up and missed opportunities for treatment (Rager 2001). In most low-income countries, access to laboratory-based testing is limited, and treatment is often restricted to those presenting with recognized clinical syndromes. Syndromic management allows same-day treatment but is known to miss infections, particularly in women, and also lacks specificity (WHO 2004). As an alternative, rapid tests, applied at the point of care, are being developed and evaluated. At present, there is wide variability in the accuracy of these tests (Núñez-Forero 2012). Other concerns about clinic-based testing include lack of privacy, confidentiality, a sense of discrimination, and prejudice, which are common in people who seek care for sexual complaints (Graseck 2011; Shih 2011).

\section{Description of the intervention}

CT and NG case management strategies that are based on making etiological rather than syndromic diagnoses include: specimen collection, diagnosis, treatment with a specific antibiotic, management of sexual partners, and follow-up.

Home-based specimen collection is an alternative to clinic-based specimen collection. Case management that uses home-based specimen collection might differ from clinic-based procedures in several ways (Table 1). First, home-based specimen collection reduces the total number of clinic visits. Second, the type of specimen might differ; home-collection requires non-invasive speci- 
mens but clinic-based strategies can use either non-invasive specimens or conventional swab sites. Specimen transport conditions and processes for ensuring follow-up for treatment might also differ (Graseck 2011; Shih 2011). Non-invasive specimen types, including first-catch urine from men and vaginal swabs for women have high sensitivity and specificity with NAAT and results from home-collected specimens are as good as those based on physician-collected specimens (Hobbs 2008; Masek 2009). Case management activities common to strategies based on both homecollected and clinic-collected specimens are: laboratory processing; informing the patient of the test result; providing treatment; notification and treatment of sexual partner(s); and follow-up (UNAIDS 1999).

Home-based specimen collection gives the responsibility for collecting the sample to the individual, and overcomes the potential barrier of attending a clinical setting for initial assessment (Graseck 2011; Shih 2011). Several large-scale studies have investigated home-collection of specimens, including studies in Denmark (Andersen 2002), the United Kingdom (Macleod 2005; Scott 2007), Sweden (Novak 2006), and the Netherlands (Götz 2006; Van Bergen 2006). Home-based specimen collection is feasible, practical and acceptable, and is often preferred by patients who have experienced both home- and clinic-based specimen collection (Graseck 2011; Shih 2011).

\section{How the intervention might work}

Home-based specimen collection as a part of case management might improve the control of CT and NG infection and decrease costs if it reduces losses in the clinical pathway from infection to cure, and results in more infected people and their sexual partners being treated for STIs. Higher uptake of early diagnosis and treatment might decrease complications like PID, ectopic pregnancy and infertility if it reduces the risk of ascending infection and does not increase reinfection rates (Low 2006).

Strategies for home-collected sampling could have advantages over clinic-based strategies as they do not require the initial clinic visit or a clinical examination (Graseck 2011). Barriers to testing in both women and men could be reduced by self-collection of samples comfortably at home or privately by the patient in the clinic. Avoidance of anxiety and fear that might occur in clinical practice could also increase adherence to home-based sampling. Qualitative data suggest that individuals who have undergone home-collected sampling prefer the simplicity, security, and privacy of selfcollected specimens (Chernesky 2005; Gaydos 2006).

\section{Why it is important to do this review}

Currently, there is no clear evidence about the effects on clinical case management of strategies for taking samples at home for testing for CT and NG compared with taking samples in the clini- cal setting. A systematic review would identify the strategies that have been evaluated, and their relative effectiveness and safety, and would allow the exploration of factors such as time to diagnosis, complete testing, and adequate treatment that might influence the strategy's effectiveness for CT and NG case management.

\section{O B J E C T I V E S}

To assess the effectiveness and safety of home-based specimen collection as part of the management strategy for Chlamydia trachomatis and Neisseria gonorrhoeae infections compared with clinic-based specimen collection in sexually-active people.

\section{METHODS}

\section{Criteria for considering studies for this review}

\section{Types of studies}

We included randomized controlled trials (RCTs) in this review; we accepted randomization at the level of individuals or clusters. We excluded cross-over trials and quasi-randomized designs. Cross-over trials are not appropriate because the intervention has a lasting effect that would compromise entry to subsequent periods of a trial. We included all relevant RCTs regardless of their publication status or language.

\section{Types of participants}

We included sexually-active people, women and men who were recruited in clinical settings, such as primary care centres and specialized clinics, or by means of population registers. We also included high-risk people such as men who have sex with men (MSM), commercial sex workers or patients diagnosed with another STI. The participants could be symptomatic or asymptomatic. We included patients with previous infection by Chlamydia trachomatis (CT) or Neisseria gonorrhoeae (NG) or the partners of individuals diagnosed with either CT or NG. There were no restrictions by age or type of sexual intercourse.

\section{Types of interventions}

We compared home-based specimen collection as part of a clinical management strategy for CT and NG with clinic-based specimen collection. The home-collected sample is taken by the participant and returned for laboratory testing. Clinic-based specimen collection could be done by clinical staff or by the participant at the clinic. This is a complex intervention and differences in the interventions are listed in Table 1. 


\section{Types of outcome measures}

\section{Primary outcomes}

- Index case management: number tested (with home- or clinic-collected sample), diagnosed and treated for CT or NG or both with a specific antibiotic, as a proportion of all participants (UNAIDS 1999).

- Harms of testing (psychological trauma, over-diagnosis, over-treatment, using definitions described by the authors).

\section{Secondary outcomes}

The first set of secondary outcomes includes the individual components of the intervention (testing, diagnosis and treatment):

- Proportion of individuals tested: number of individuals who provide a specimen for CT or NG testing divided by the number of participants;

- Positive test prevalence: number of infections identified divided by the number of people tested;

- Proportion of infections treated: number of people treated divided by number of positive tests.

The second set of secondary outcomes includes additional activities that are part of comprehensive STI case management, but are not part of the primary outcome:

- Proportion of sexual partners receiving treatment: number of sexual partners receiving treatment divided by the number of sexual partners of the individuals treated;

- Infection cured: number of individuals treated who have evidence of being free from infection at least 12 months after the start of the intervention divided by the number of individuals treated.

The third set of secondary outcomes are process and economic outcomes in the pathway of STI case management:

- Barriers to testing (any reason for not completing the testing procedure);

- Feasibility (collection of the specimen reported as easy, convenient);

- Acceptability (collection of the specimen reported as comfortable, secure);

- Costs.

\section{Search methods for identification of studies}

We developed a systematic and highly-sensitive search strategy to identify as many relevant RCTs meeting the inclusion criteria as possible, irrespective of their language, publication date and publication status (published, unpublished, in press, and in progress). We used both electronic searching in bibliographic databases and handsearching, as described in the Cochrane Handbook for Systematic Reviews of Interventions (Higgins 2011).
We downloaded and managed the results of all searches using Endnote bibliographic software. We deleted duplicate records of the same study.

\section{Electronic searches}

The Trials Search Coordinator of the Sexually Transmitted Infections Cochrane Review Group implemented a comprehensive search strategy to capture as many relevant RCTs as possible in electronic databases. For this purpose, we used a combination of exploded controlled vocabulary (MeSH, EMTREE, DeCS) and free-text terms (considering spelling variants, plurals, synonyms, acronyms and abbreviations) for home-based versus clinic-based strategy for Chlamydia trachomatis and Neisseria gonorrhoeae detection, with field labels, truncation, proximity operators and Boolean operators. The sensitivity of the search strategies was improved by including keywords from relevant RCTs detected by earlier searches. We present the search strategies in Appendix 1. Specifically, we searched the following electronic databases.

- The Cochrane Central Register of Controlled Trials (CENTRAL), Ovid platform (1991 to 27 May 2015).

- MEDLINE, Ovid platform (January 1946 to 27 May 2015).

- MEDLINE In-Process \& Other Non-Indexed Citations, Ovid platform (1946 to 27 May 2015).

- MEDLINE Daily Update, Ovid platform (1946 to 27 May 2015).

- EMBASE.com (1947 to 27 May 2015).

- LILACS, iAHx interface (1982 to 27 May 2015).

To search MEDLINE we used the Cochrane Highly Sensitive Search Strategy for identifying RCTs: sensitivity and precision maximizing version (2008 revision), Ovid format (Higgins 2011). We combined the LILACS search strategy with the RCT filter for the iAHx interface.

These searches have been updated within 6 months before publication of the review.

\section{Searching other resources}

We attempted to identify additional relevant RCTs by: 1. Searching the Sexually Transmitted Infections Cochrane Review Group's Specialized Register, which includes RCTs and controlled clinical trials, from 1944 to 2012, located through:

- Electronic searching in MEDLINE, EMBASE and CENTRAL; and

- Online handsearching in those journals not indexed in MEDLINE or EMBASE, according to the journals' master list of the STI Cochrane Review Group.

2. Searching trials registers:

- World Health Organization (WHO) International Clinical Trials Registry Platform (ICTRP) portal (http://apps.who.int/ trialsearch/) (searched 27 May 2015); 
- ClinicalTrials.gov (http://clinicaltrials.gov/) (searched 27 May 2015).

3. Searching for gray literature in the System for Information on Grey Literature in Europe "OpenGrey" (http:// www.opengrey.eu/) (searched 27 May 2015).

4. Contacting authors of all RCTs identified by other methods. A comprehensive list of RCTs included in the review along with the criteria for considering studies was sent to the first author of each included study, with a request for any additional studies, published or unpublished, that might be relevant.

5. Handsearching conference proceeding abstracts from the following events:

- The International Society for Sexually Transmitted Diseases Research - ISSTDR (http://www.isstdr.org/): 2007, 2009 and 2011.

- The British Association for Sexual Health and HIV BASHH (http://www.bashh.org/): 2004, 2006, 2007 and 2009.

- International Congress on Infectious Diseases - ICID ( http://www.isid.org/): 2010 and 2012.

- The International Union against Sexually Transmitted Infections - IUSTI (http://www.iusti.org/): 2011 and 2012.

- International Society for Infectious Diseases - ISID (http:// www.isid.org/): 2011.

- International Meeting on Emerging Diseases and Surveillance - IMED (http://www.isid.org/): 2007, 2009 and 2011.

- Interscience Conference on Antimicrobial Agents and Chemotherapy - ICAAC (http://www.icaac.org/): 2011 and 2012.

- The International Federation of Gynecology and Obstetrics - FIGO (http://www.figo2012.org/home/): 2012.

6. Handsearching previous systematic reviews and other relevant publications on the same topic.

7. Handsearching reference lists of all relevant RCTs identified by other methods.

\section{Data collection and analysis}

\section{Selection of studies}

Assessment of eligibility of studies was conducted by three authors separately (LF, JA, PV) who examined each title and abstract to exclude irrelevant reports. The full-length articles of the selected titles or abstracts were screened against the inclusion criteria. Multiple reports of the same study were linked together. We resolved disagreements by discussion. If there was still a disagreement, a fourth author made the final decision (HG).

\section{Data extraction and management}

PV, JA and LF extracted data from each of the included trials independently using a data extraction form designed by the authors. Differences were resolved by discussion and the consensus entered into a new form. EA checked the completed consensus form against the original papers. The data extraction form was pilot tested using one of the included studies. If there were multiple publications relating to the same study, we extracted data from all reports into a single data extraction form. If items reported in different publications were inconsistent, we used the primary publication as the source document. The primary publication was that which reported the primary outcome.

We extracted the following data:

- Methodology: trial design, identified population, sample size, location of the study, blinding and statistical methods; baseline information on the participants in order to have comparable intervention and control groups at entry; methods used to generate random allocation, methods used to maintain allocation concealment; and use of intention-to-treat analysis.

- Participants: number, source, age, gender, inclusion and exclusion criteria, recruitment site, previous investigations and treatments, co-morbidities, history of STIs, use of contraception, number of sexual partners, number of participants enrolled, randomized, excluded after randomization, and analyzed.

- Interventions: type of testing carried out in home-based testing group and intervention described in control group; instructions about how to collect the specimen; processes involved in patient- or provider-collected samples; devices used for taking the specimen; specimen transport conditions; processes for handling the sample at the site where it will be processed; accuracy of the underlying tests; processes for sending results to providers; processes for informing patients about their test results and ensuring follow-up for treatment; antibiotic treatment; notification and treatment of sexual partner(s); time to follow-up and results; other interventions in the groups under evaluation.

- Outcomes: number of individuals tested, diagnosed and treated for CT and NG; number of individuals treated and having evidence of freedom from infection during period of RCT; positive test prevalence (number of infections identified/ number of subjects tested); number of individuals who completed testing for CT or NG; number of infections treated; number of sexual partners receiving treatment; number of individuals not tested at the end (sample was not obtained); adverse effects of testing; barriers to testing; feasibility; acceptability; number of patients receiving treatment, positive test prevalence; costs.

- Reported funding sources and conflicts of interest.

- Ethical issues: use of signed informed consent and ethics approval. 
We extracted the data and then we checked and entered them into Review Manager 5 (RevMan) software.

\section{Assessment of risk of bias in included studies}

Two review authors (LF, PV) independently assessed the risk of bias within each included study by addressing six specific domains, using the 'Risk of bias' assessment tool (Higgins 2011). We assessed: sequence generation; allocation concealment; blinding of participants, providers and outcome assessors; completeness of outcome data; selective outcome reporting; and other potential sources of bias. LF and PV compared the results and in case of disagreement between them, we made the decision by consensus.

For each included study, the review authors made a decision by assigning a judgement of 'low risk' of bias, 'high risk' of bias, or 'unclear risk' of bias for the following domains:

\section{(I) Random sequence generation (checking for possible selection bias)}

For each included study we described the method used to generate the allocation sequence in sufficient detail to allow an assessment of whether it should produce comparable groups.

We assessed the method as:

- low risk (any truly random process, e.g. random number table; computer random number generator);

- high risk (any non-random process, e.g. odd or even date of birth; hospital or clinic record number);

- unclear risk, if the trial is described as randomized, but the method used for the allocation sequence generation is not described.

\section{(2) Allocation concealment (checking for possible selection bias)}

For each included study we described the method used to conceal the allocation sequence in sufficient detail and determine whether intervention allocation could have been foreseen in advance of, or during recruitment, or changed after assignment.

We assessed the methods as:

- low risk (e.g. telephone or central randomization; consecutively numbered sealed opaque envelopes);

- high risk (open random allocation; unsealed or non-opaque envelopes; alternation; date of birth);

- unclear risk, if the trial is described as randomized but the method used to conceal the allocation is not described.

\section{(3.I) Blinding of participants and personnel (checking for possible performance bias)}

We restricted assessment of blinding to blinding of outcome assessors, since it is not possible to blind participants and personnel to strategy of sample collection.
(3.2) Blinding of outcome assessment (checking for possible detection bias)

We described for each included study the methods used, if any, to blind outcome assessors from knowledge of which intervention a participant received. We assessed blinding separately for subjective outcomes (adverse effects of testing, barriers to testing, feasibility, acceptability) and objective outcomes (being tested, diagnosed, treated and having evidence of freedom from infection for CT and NG, positive test prevalence, number of sexual partners receiving treatment, number of individuals not tested at the end, costs).

We assessed methods used to blind outcome assessment as low, high or unclear risk of bias.

(4) Incomplete outcome data (checking for possible attrition bias due to the amount, nature and handling of incomplete outcome data)

We described for each included study, and for short-term outcomes (being tested, being diagnosed, positive test prevalence, adverse effects of testing, barriers to testing, feasibility, acceptability) and long-term outcomes (treated and having evidence of freedom from infection, number of individuals not tested, number of sexual partners receiving treatment, costs), the completeness of data including attrition and exclusions from the analysis. We stated whether attrition and exclusions were reported and the numbers included in the analysis at each stage (compared with the total randomized participants), reasons for attrition or exclusion where reported, and whether missing data were balanced across groups or were related to outcomes. Where trial authors reported or supplied sufficient information, we re-included missing data in the analyses which we undertook.

We assessed methods as:

- low risk of bias (e.g. no missing outcome data; missing outcome data balanced across groups);

- high risk of bias (e.g. numbers or reasons for missing data imbalanced across groups; 'as treated' analysis done with substantial departure of intervention received from that assigned at randomization, $>20 \%$ of missing data);

- unclear risk of bias.

\section{(5) Selective reporting bias (checking for reporting bias)}

We described for each included study how we investigated the possibility of selective outcome reporting bias and what we found. We assessed the methods as:

- low risk of bias (where it is clear that all of the study's prespecified outcomes and all expected outcomes of interest to the review have been reported);

- high risk of bias (where not all of the study's pre-specified outcomes have been reported; one or more reported primary outcomes were not pre-specified; outcomes of interest are reported incompletely and so cannot be used; study fails to 
include results of a key outcome that would have been expected to have been reported);

- unclear risk of bias.

(6) Other bias (checking for bias due to problems not covered by (I) to (5) above)

We described for each included study any important concerns we have about other possible sources of bias. We assessed whether each study was free of other problems that could put it at risk of bias:

- low risk of other bias;

- high risk of other bias;

- unclear whether there is risk of other bias.

\section{(7) Overall risk of bias}

We made explicit judgements about whether studies were at high risk of bias, according to the criteria given in the Cochrane Handbook for Systematic Reviews of Interventions (Higgins 2011). With reference to (1) to (6) above, we assessed the likely magnitude and direction of the bias and whether we considered it is likely to impact on the findings. We explored the impact of the level of bias through undertaking sensitivity analyses - see Sensitivity analysis. We created a 'Risk of bias' table to report on the risk of bias in included studies.

\section{Measures of treatment effect}

We expressed dichotomous outcomes as the risk ratio (RR) with $95 \%$ confidence intervals (CI).

\section{Unit of analysis issues}

\section{Cluster-randomized trials}

The unit of analysis for most trials was the individual. Ostergaard 1998 employed cluster randomization and did not take the unit of allocation and cluster design into account in their analysis. We asked the authors for more information but we did not receive a reply. The authors analyzed data from individuals rather than the cluster. We therefore extracted the average cluster size (524) and the number of clusters randomized (17), and used an intracluster correlation coefficient (ICC) of 0.00119 , obtained from a published external source (Ukoumunne 1999). We followed the methods stated in the Cochrane Handbook for Systematic Reviews of Interventions to analyze the data (Higgins 2011). If heterogeneity among the included studies seemed to be meaningful and the effect of the intervention was strongly associated with the unit of randomization, we examined the results after excluding the cluster-randomized trial.

\section{Dealing with missing data}

We reported the percentage of observations with missing data in each included trial. We performed sensitivity analysis including or excluding trials with high levels of missing data to explore the impact of missing data in the overall assessment of the intervention. For all outcomes, we analyzed results with all participants in the group to which they were allocated, excluding only participants with missing outcome data. The denominator for each outcome in each trial was the number randomized minus any participants whose data are known to be missing. We communicated with the authors of the included studies to obtain missing data.

\section{Assessment of heterogeneity}

We explored heterogeneity by visual inspection of the forest plot and with an $\mathrm{I}^{2}$ and tau statistic and $\mathrm{Chi}^{2}$ tests (Higgins 2003). We judged heterogeneity as considerable if $\mathrm{I}^{2}$ was greater than $50 \%$ or if the $\mathrm{P}$ value in the $\mathrm{Chi}^{2}$ test was less than 0.10 .

\section{Assessment of reporting biases}

We did not find a sufficient number of studies (more than 10) to include in the meta-analysis, so we did not produce funnel plots to investigate reporting biases.

\section{Data synthesis}

We used narrative and descriptive synthesis to explore the results from the third group of secondary outcomes. We performed statistical analysis using Review Manager 5 (RevMan). Data were pooled using a fixed-effect model or random-effects model, as appropriate, depending on the level of heterogeneity. The fixed-effect model of meta-analysis was applied if the studies estimated the same intervention effect. This was conducted with the aim of combining the results. Otherwise, if clinical and statistical heterogeneity were substantial, then we used a random-effects model to summarize the effects of the intervention. The results were presented as the summary RR $(95 \% \mathrm{CI})$ with $\mathrm{I}^{2}$ and tau ${ }^{2}$ statistic. The Mantel-Haenszel (M-H) method was used to conduct metaanalysis of dichotomous data. The inverse variance (IV) method was used for continuous data.

\section{'Summary of findings' table}

We summarized the results for the main comparison of homebased versus clinic-based specimen collection for CT and NG detection in 'Summary of findings' tables (Schünemann 2011a). We used the GRADE approach to assess the quality of evidence in relation to each outcome included (Schünemann 2011b); and used GRADE profiler (GRADEpro) software to import data from RevMan 5 to create 'Summary of findings' tables (RevMan). We report the following main outcomes in the 'Summary of findings' table, in terms of their importance for decision-making: 
- Index case management;

- Proportion of individuals tested;

- Positive test prevalence;

- Adverse effects of testing;

We downgraded the quality of evidence depending on the presence of the five GRADE considerations (study limitations; inconsistency of results; indirectness of evidence; imprecision; and publication bias).

\section{Subgroup analysis and investigation of heterogeneity}

We planned to perform a subgroup analysis to explore heterogeneity according to:

- Sex of the patient;

- Returning specimens by mail or in person, which might influence intervention adherence;

- Notification and treatment at clinic or sent to home, which might be related to adherence and accessibility to treatment and diagnosis;

- Level of sexual behavior risk of the study population (groups at high risk of CT or NG: patients whose partners have a diagnosis of CT and NG, patients who are undertaking repeat testing following treatment for CT or NG, sex workers, people with HIV infection, MSM);

- Pregnant women: pregnancy could influence adherence to diagnosis, treatment and follow-up;

- Adolescent: age below 18 years might be related to poor adherence to diagnosis, treatment and follow-up.

For fixed-effect models based on inverse variance meta-analysis, we assessed differences between subgroups by interaction tests (Deeks 2001). For random-effects models we performed stratified analyses and used meta-regression to estimate the ratio of risk ratios (RRR, with $95 \% \mathrm{CI}$ ), comparing studies with the characteristic of interest with those without (using the command "metareg" in Stata). We performed one subgroup analysis that was not pre-specified in the protocol of this review. We examined the intervention effect according to the use of reminders. Intervention effects might have differed between trials that did or did not use reminders to increase test uptake.

\section{Sensitivity analysis}

We planned to perform sensitivity analysis taking into account the possibility that the quality of the studies, the inclusion of cluster RCTs, different ICCs in the analysis of cluster-randomized trials and the variation in the imputed values for missing data may have influenced the results. We performed sensitivity analysis for outcomes with statistical heterogeneity using different statistical models, that is, fixed-effect and random-effects models.

\section{R E S U L T S}

\section{Description of studies}

\section{Results of the search}

The search of electronic databases on 27 May 2015 yielded 730 records, of which 197 were duplicate records. We reviewed the titles and abstracts of 533 records and discarded 508 records. We examined the full text of the remaining 25 records. We included 10 published studies that met our inclusion criteria (Andersen 1998; Ostergaard 1998; Ostergaard 2003; Cook 2007; Jones 2007; Lippman 2007; Graseck 2010; Xu 2011; Reagan 2012; Götz 2013; see Figure 1). The search of other sources did not identify any new records. We excluded 12 full-text articles (see Characteristics of excluded studies). In addition, we excluded trials by Andersen 2002, Scholes 2007 and Klovstad 2013 because the comparison was usual care, rather than clinic-based specimen collection from all patients in a clinic that met the criteria for Chlamydia trachomatis (CT) or Neisseria gonorrhoeae (NG) testing. 
Figure I. Study flow diagram.

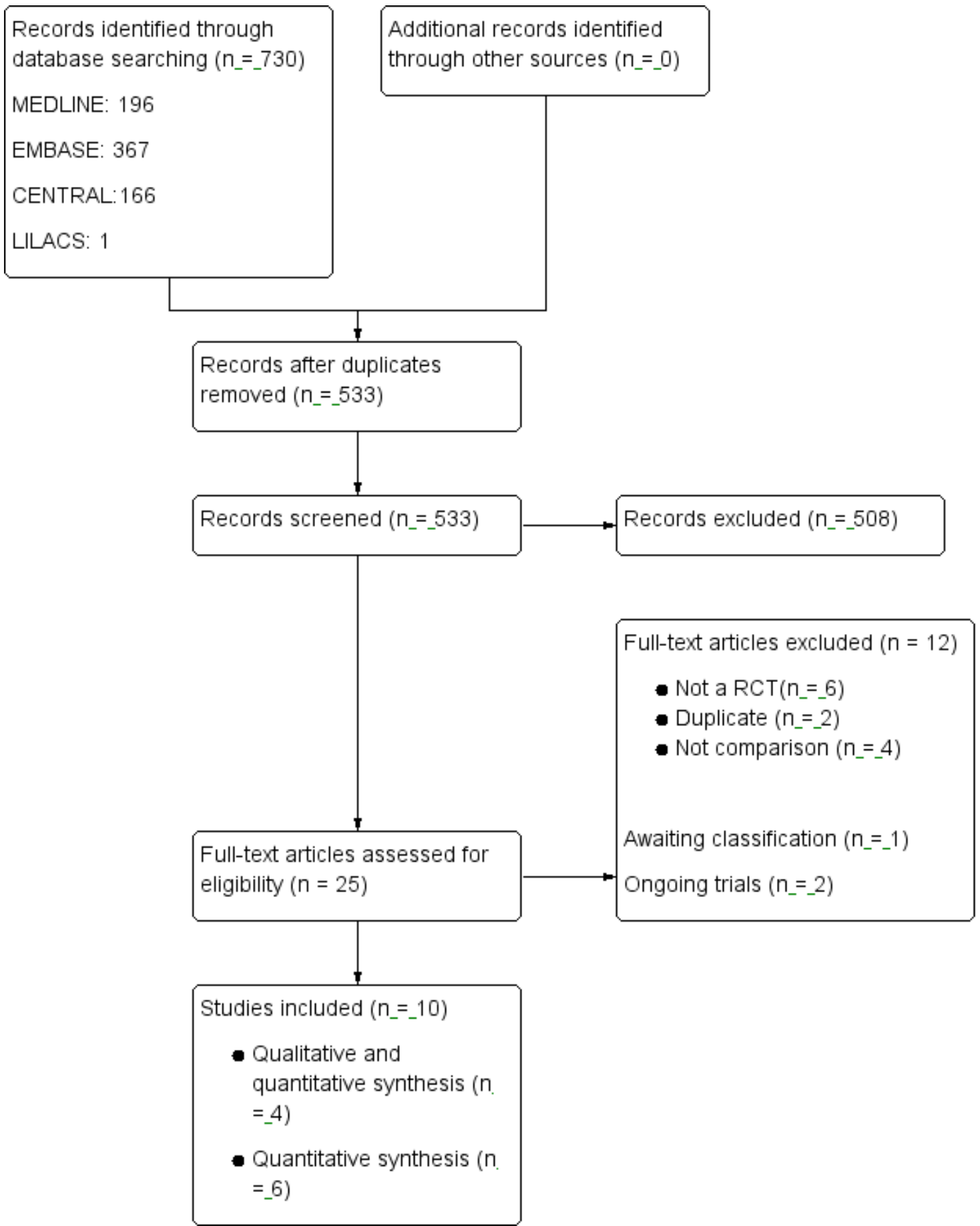


One trial (Apoola 2009) was classified as 'awaiting classification' because outcome data were not available (see Characteristics of studies awaiting classification). We contacted the study authors, but they did not provide information. We found two ongoing studies as a result of the search (De Barbeyrac 2013; Smith 2014; see Characteristics of ongoing studies).

\section{Included studies}

The 10 RCTs included 10,479 participants (see Characteristics of included studies). These trials were three from Denmark (Andersen 1998; Ostergaard 1998; Ostergaard 2003), four from USA (Cook 2007; Graseck 2010; Xu 2011; Reagan 2012), and one each from Netherlands (Götz 2013), Brazil (Lippman 2007), and South Africa (Jones 2007). In most trials, recruitment was based in community clinics (Cook 2007; Jones 2007; Lippman 2007; Graseck 2010; Reagan 2012). Two trials enrolled participants from STI clinics (Xu 2011; Götz 2013), two from general practices (Andersen 1998; Ostergaard 2003), and one recruited from 17 high schools in a cluster RCT (Ostergaard 1998). Six trials carried out a valid method for sample size calculation in advance (Cook 2007; Jones 2007; Graseck 2010; Xu 2011; Reagan 2012; Götz 2013). In the study by Xu 2011 the authors described their two RCTs but we considered this as a single trial that used stratified randomization. All included studies were published in English.

\section{Participants}

Five trials evaluated patients having high risk of STIs; two trials were conducted among patients with previous CT infection and evaluated retesting (Xu 2011; Götz 2013), two trials (Andersen 1998; Ostergaard 2003) evaluated testing of sexual partners of CT positive individuals (one of which included male partners of female index patients only, Andersen 1998), and one included women with a recent diagnosis of STI or an increased risk of acquiring a STI (Cook 2007). Five trials included women only (Cook 2007; Jones 2007; Lippman 2007; Graseck 2010; Xu 2011), and two included men only (Andersen 1998; Reagan 2012). The remaining trials included both male and female participants (Ostergaard 1998; Ostergaard 2003; Götz 2013). The trials included 3138 men and 7341 women. Götz 2013 did not report the sex of participants according to the group assignment.

\section{Interventions}

In three trials, authors stated that they allocated participants to home-based or clinic-based specimen collection, analysed specimens, gave results and provided antibiotic treatment (Lippman 2007; Graseck 2010; Reagan 2012). Graseck 2010 also reported that women were given antibiotics for all sexual partners.
In five trials, participants took their own swabs in both the homeand clinic-based groups (Jones 2007; Lippman 2007; Graseck 2010; Reagan 2012; Götz 2013). In the other five trials, clinic staff took the specimens in the clinic-based group (Andersen 1998; Ostergaard 1998; Ostergaard 2003; Cook 2007; Xu 2011).

For trials that included women only, three compared home-collected vaginal swabs with vaginal swabs collected at a clinic (Jones 2007; Lippman 2007; Graseck 2010). The other two trials compared home-collected vaginal swabs with an appointment to return to clinic for testing but did not state the clinic procedures for specimen collection (Cook 2007; Xu 2011).

For trials that included men: Andersen 1998 evaluated homecollected first catch urine specimen versus a referral to a clinic for urethral specimen collection. Reagan 2012 compared homecollected urine specimens with urine specimens collected at the clinic.

For trials that enrolled both women and men, one evaluated homecollected urine specimens for men and vaginal swabs for women versus an invitation to attend the clinic where the same specimen types were collected (Götz 2013). Ostergaard 1998 compared home-collected specimens from women (two urine specimens and a vaginal flush specimen) and men (first catch urine specimen) with an offer of clinic-based sampling with unspecified specimen types. Ostergaard 2003 sent specimen collection kits to index patients with chlamydia and assigned them at random to telling partners to collect specimens at home and mail them to the laboratory, or bringing the specimen kit to a clinic and providing the specimen at the clinic. Female partners collected vaginal flush specimens and male partners provided first catch urine specimens. Participants in the home-based specimen collection groups sent their samples to the laboratory by mail in all trials but one, in which they brought their home-taken sample to the clinic for laboratory testing (Lippman 2007).

All trials used NAATs for diagnosis. Five trials tested specimens for CT infection only (Andersen 1998; Ostergaard 1998; Ostergaard 2003; Xu 2011; Götz 2013). Three trials tested for CT and NG (Cook 2007; Graseck 2010; Reagan 2012); and two trials tested for CT, NG and Trichomonas vaginalis (TV) (Jones 2007; Lippman 2007).

Some trials used reminders to encourage adherence to study interventions (Jones 2007; Lippman 2007; Xu 2011; Götz 2013). Andersen 1998, Ostergaard 1998 and Ostergaard 2003 did not report the use of reminders. Reagan 2012 did not use reminders but gave a monetary incentive of $\$ 10$ gift card to the participants. Cook 2007 and Graseck 2010 explicitly stated that they did not use any kind of reminder. In this review, for the secondary outcome 'proportion of individuals tested', we classified Cook 2007 as having used reminders, because the authors report the proportion of participants who completed at least one test during the two

Home-based versus clinic-based specimen collection in the management of Chlamydia trachomatis and Neisseria gonorrhoeae 
year trial period, which included three invitations to be tested.

\section{Outcomes}

The prespecified primary outcomes were not completely evaluated in the included trials. None of the included trials had an authordefined outcome that fulfilled our definition of index case management. Only three trials allowed the outcome of index case management to be assessed and none specified the antibiotic treatment used (Lippman 2007; Graseck 2010; Reagan 2012). The evaluation and reporting of treatment of infected participants were not clearly stated in the remaining trials (Andersen 1998; Ostergaard 1998; Ostergaard 2003; Cook 2007; Jones 2007; Xu 2011; Götz 2013). No trials reported adverse effects of testing.

In the first set of secondary outcomes, all trials reported the proportion of individuals tested. This was the primary outcome stated by the authors of these trials. The authors of all but Cook 2007 also reported the positive test prevalence. Cook 2007 reported rates of positive tests per 100 woman-years of follow-up. The number of infected individuals receiving treatment was mentioned in only three trials (Lippman 2007; Graseck 2010; Reagan 2012).

For the second set of secondary outcomes, no trial reported the proportion of sexual partners receiving treatment or measured the proportion of infections cured. Although the participants in two trials were sexual partners of index cases the investigators did not evaluate the management of other sexual partners (Andersen 1998;
Ostergaard 2003).

Outcomes in the third set of secondary outcomes were evaluated in four trials. Two trials described the results of surveys and reported information about feasibility and acceptability (Jones 2007; Lippman 2007). We found an economic evaluation of the trial by Cook 2007 (Smith 2007). This was a cost comparison without a cost-effectiveness analysis. Graseck 2010 evaluated barriers to testing in participants who did not complete testing.

\section{Excluded studies}

We excluded 12 full-text articles (Characteristics of excluded studies). Six articles were not RCT (Gray 1998; Van Valkengoed 2002; Sparks 2004; Buhrer-Skinner 2011; Emmerton 2011; Falk 2014; ). Four studies did not evaluate the comparison specified in the protocol because participants in the control group were tested only if they had symptoms (Andersen 2002; Scholes 2007; Andersen 2011; Klovstad 2013). Ostergaard 1999 was a duplicate from Ostergaard 1998 in Danish. Ostergaard 2000 reported the follow-up to the primary report (Ostergaard 1998).

\section{Risk of bias in included studies}

The risk of bias for each included study is presented in the 'Risk of bias' table in the section Characteristics of included studies. Figure 2 and Figure 3 illustrate the summary of risk of bias assessment in included studies. 
Figure 2. Risk of bias summary: review authors' judgements about each risk of bias item for each included study.

\begin{tabular}{|c|c|c|c|c|c|c|c|c|c|}
\hline & 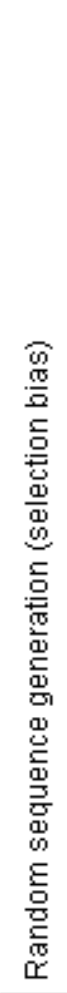 & 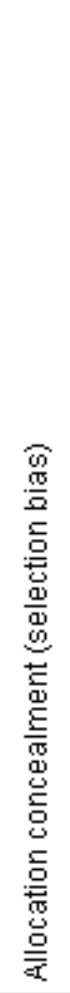 & 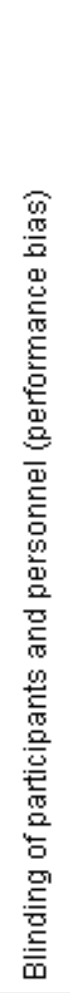 & 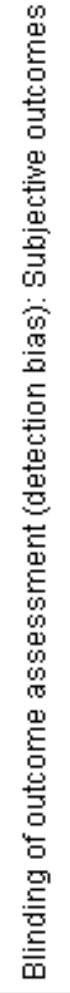 & 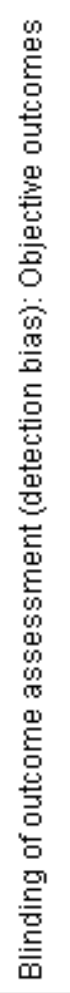 & 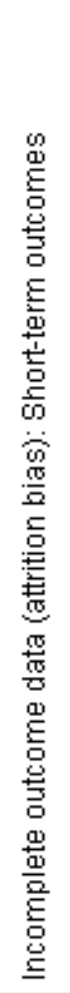 & 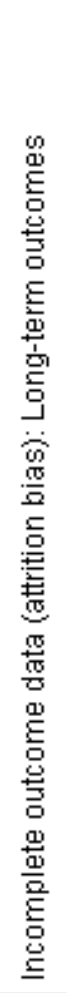 & 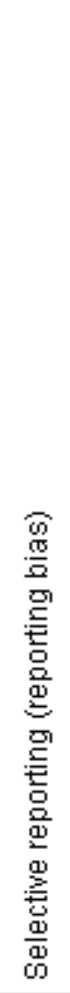 & 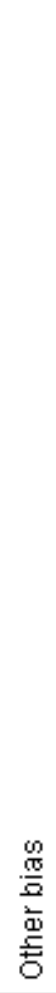 \\
\hline Andersen 1998 & - & $?$ & $\odot$ & $?$ & $?$ & - & $?$ & $?$ & \\
\hline Cook 2007 & $\odot$ & + & - & $?$ & + & $?$ & $?$ & + & $?$ \\
\hline Göt 2013 & + & $?$ & 0 & $?$ & - & $\odot$ & $?$ & $?$ & \\
\hline Graseck 2010 & + & + & & $\odot$ & - & 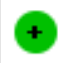 & $?$ & + & $\odot$ \\
\hline Jones 2007 & $?$ & + & 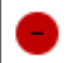 & - & - & $?$ & $?$ & $?$ & \\
\hline Lippman 2007 & + & + & & $?$ & $?$ & + & $?$ & $?$ & \\
\hline Ostergaard 1998 & $?$ & $?$ & ก & $?$ & $?$ & - & $?$ & $?$ & $?$ \\
\hline Ostergaard 2003 & $?$ & + & & $?$ & ? & 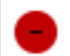 & $?$ & $?$ & \\
\hline Reagan 2012 & + & $?$ & & $?$ & $\odot$ & 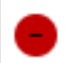 & $?$ & + & \\
\hline Xu 2011 & $\odot$ & + & - & $?$ & $?$ & 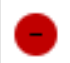 & $?$ & + & \\
\hline
\end{tabular}

Home-based versus clinic-based specimen collection in the management of Chlamydia trachomatis and Neisseria gonorrhoeae 
Figure 3. Risk of bias graph: review authors' judgements about each risk of bias item presented as percentages across all included studies.

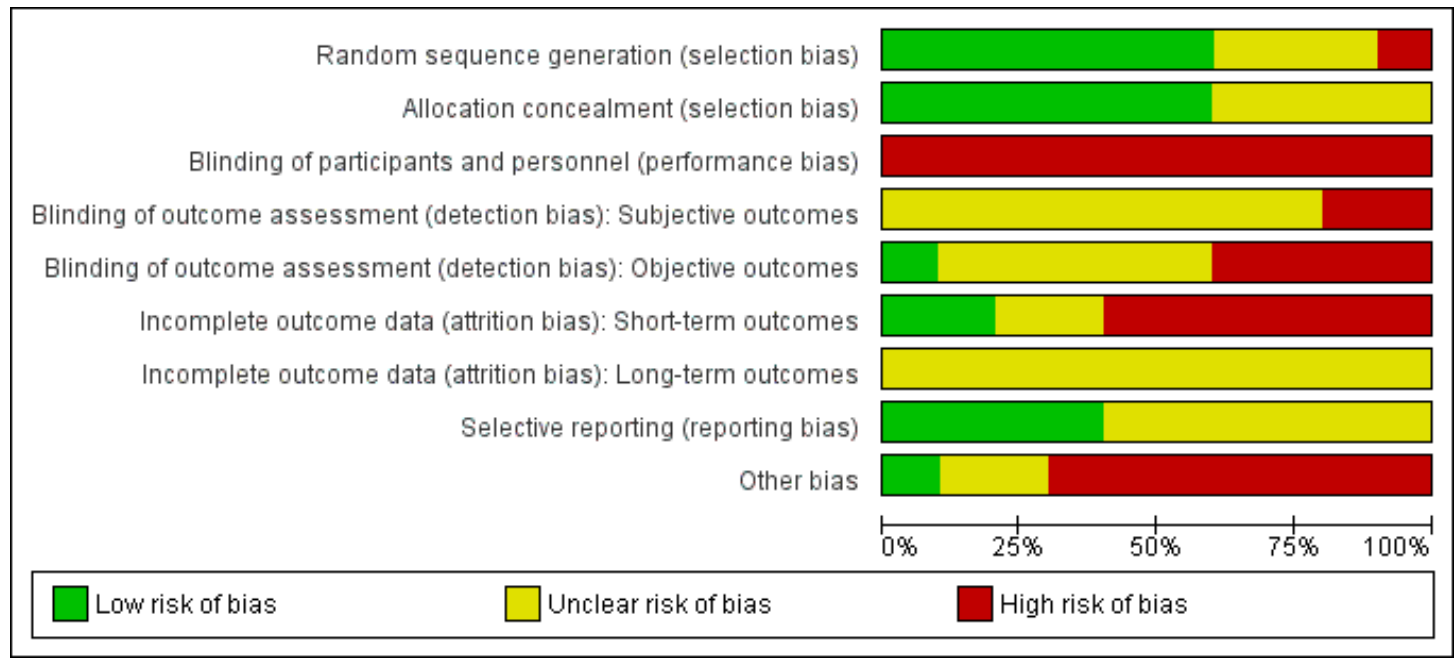

\section{Allocation}

\section{Random sequence generation}

Six trials adequately reported a random sequence generation method. Of these trials, three used computer-generated, blocked randomization (Cook 2007; Lippman 2007; Xu 2011); and three trials used computer-generated random number lists (Graseck 2010; Reagan 2012; Götz 2013). One trial reported that the date of birth of index patient was used to allocate participants to intervention and control groups, and was judged to be at high risk of bias (Andersen 1998). In the remaining included trials the random sequence generation was unclear (Ostergaard 1998; Ostergaard 2003; Jones 2007).

\section{Allocation concealment}

Six trials reported adequate allocation concealment. Of these, four trials reported the use of sealed, sequentially numbered envelopes (Cook 2007; Jones 2007; Lippman 2007; Xu 2011); one trial reported the use of a central randomization (Ostergaard 2003); and in one trial the participants had no knowledge of allocation until time of testing (Graseck 2010).

In the four remaining, the methods used for allocation concealment were not adequately described, making the risk of selection bias at entry unclear (Andersen 1998; Ostergaard 1998; Reagan 2012; Götz 2013).

\section{Blinding}

Blinding of participants and personnel (performance bias)

It is not possible to blind participants and personnel to different specimen-collection methods (Andersen 1998; Ostergaard 1998; Ostergaard 2003; Cook 2007; Jones 2007; Lippman 2007; Graseck 2010; Xu 2011; Reagan 2012; Götz 2013). Knowledge of the assigned strategy might influence adherence to testing and intervention compliance, so we judged all trials as being at high risk of performance bias.

\section{Blinding of outcome assessment (detection bias)}

\section{Subjective outcomes}

Seven trials did not report subjective outcomes (adverse effects of testing, barriers to testing, feasibility, acceptability) and were judged as being at unclear risk of detection bias (Andersen 1998; Ostergaard 1998; Ostergaard 2003; Cook 2007; Xu 2011; Reagan 
2012; Götz 2013). One trial evaluated barriers to testing without blinding and was judged as being at high risk of detection bias (Graseck 2010). Two trials reported feasibility and acceptability outcomes; Jones 2007 was unblinded and judged as being at high risk of detection bias, and Lippman 2007 did not provide sufficient information so was judged as unclear risk of bias.

\section{Objective outcomes}

All trials reported some objective outcomes. Five trials did not provide sufficient information about blinding of outcome assessors so the risk of bias was unclear (Andersen 1998; Ostergaard 1998; Ostergaard 2003; Lippman 2007; Xu 2011). One trial was judged as low risk of bias since outcome assessors were blinded to participants assignment (Cook 2007). Four trials were unblinded and judged as being at high risk of bias (Jones 2007; Graseck 2010; Reagan 2012; Götz 2013).

\section{Incomplete outcome data}

\section{Short-term outcomes}

With respect to short-term outcomes (being tested, being diagnosed, positive test prevalence, adverse effects of testing, barriers to testing, feasibility, acceptability), only one trial had an attrition rate of less than $20 \%$ (Lippman 2007); 96\% of participants were tested in this study, so was judged as low risk of bias. Eight trials were at high risk of attrition bias with more than $20 \%$ lost to follow-up and imbalances between groups (Andersen 1998; Ostergaard 1998; Ostergaard 2003; Xu 2011;Reagan 2012; Götz 2013). Attrition rates in Cook 2007 and Jones 2007 were high but balanced in the intervention groups, so we judged these trials as being at unclear risk of attrition bias. In Graseck 2010 they had tests for 151/268 in the home-based group and medical records or a specimen from $163 / 280$ in the clinic-based group; this was judged as low risk of bias.

\section{Long-term outcomes}

For long-term outcomes (receiving treatment, evidence of freedom from infection, number of individuals not tested, number of sexual partners receiving treatment, costs) all trials reported the number of individuals not tested and had attrition rates greater than $20 \%$, except for Lippman 2007 where $96 \%$ completed the test and where the use of reminders was intense. No trial reported on negative test results 12 months after the treatment or the number of sexual partners receiving treatment so all had an unclear risk of bias ( Andersen 1998; Ostergaard 1998; Ostergaard 2003; Cook 2007; Jones 2007; Lippman 2007; Graseck 2010; Xu 2011; Reagan 2012; Götz 2013).

\section{Selective reporting}

We searched for trial protocols to assess reporting bias. If the trial protocol was not accessible, we looked for selective reporting in trials by searching for reports of the primary outcome in the Methods and the Results sections of the report. Protocols were available for four trials (Cook 2007; Graseck 2010; Xu 2011; Reagan 2012). We judged these four trials to have a low risk of reporting bias because the primary outcome stated in the protocol was reported in the trial result section (Graseck 2010; Xu 2011; Reagan 2012). For six trials the trial protocol was not available and it was unclear if it had been published; all reports did not clearly state the expected outcomes and therefore were judged as unclear risk of bias (Andersen 1998; Ostergaard 1998; Ostergaard 2003; Jones 2007; Lippman 2007; Götz 2013).

\section{Other potential sources of bias}

Four trials used reminders as part of their management strategy, which might increase the number of participants completing the intervention (Jones 2007; Lippman 2007; Xu 2011; Götz 2013). Participants in two trials were chlamydia positive patients, in which the study objective was to evaluate re-testing (Götz 2013; Xu 2011); and in another two trials the population objective was sexual partners of CT positive index patients (Andersen 1998; Ostergaard 2003). In Cook 2007 they recruited women with a recent diagnosis of CT, NG or TV. In these trials participants are part of a selective population where the adherence to intervention might be influenced by their previous status. We found that the cluster-RCT by Ostergaard 1998 did not take the unit of allocation and cluster design into account in their analysis.

\section{Effects of interventions}

See: Summary of findings for the main comparison Homebased compared with clinic-based specimen collection for CT and NG

See Summary of findings for the main comparison

\section{Home-based specimen collection versus clinic-based specimen collection in the management of CT and NG}

Ten trials with 10,479 participants compared home-based versus clinic-based specimen collection. Not all trials provided data for each outcome analysis. The data were obtained from published reports and it was not possible to obtain additional information from authors. Harms of testing, which was a primary outcome, was not evaluated in any trial.

\section{Primary outcomes}




\subsection{Index case management}

We extracted data from three studies about the complete management strategy, defined as participants who were tested, diagnosed and treated (Lippman 2007; Graseck 2010; Reagan 2012). A total of 1566 participants (1366 women and 200 men) were enrolled in these trials; 45 CT or NG infections were diagnosed amongst 778 participants assigned to collect specimens at home and $51 \mathrm{CT}$ or NG infections were diagnosed amongst participants assigned to clinic-based specimen collection. Graseck 2010 reported that all women with positive test results received treatment. Lippman 2007 reported that one woman did not receive treatment, but did not say in which arm of the trial. We conducted the primary analysis assuming that the untreated woman was in the home-based group and repeated it assuming she was in the clinic-based group. Reagan 2012 reported that all men with positive test results received treatment.

Meta-analysis of three trials showed no difference in the proportions with index case management strategy between home-based $(45 / 778,5.8 \%)$ and clinic-based $(51 / 788,6.5 \%)$ groups (RR 0.88 , $95 \%$ CI 0.60 to 1.29; participants $=1566$; studies $=3$; $\mathrm{I}^{2}=0 \%$, tau 0.00; Analysis 1.1; Figure 4). The result was almost the same when the untreated woman in Lippman 2007 was allocated to the clinic-based arm (RR $0.92,95 \%$ CI 0.63 to 1.35 ). We judged the quality of evidence as moderate as a result of high risks of detection and attrition bias in the included studies (Summary of findings for the main comparison).

Figure 4. Forest plot of comparison: I Home-based vs clinic-based specimen collection for CT and NG, outcome: I.I Index case management.

\begin{tabular}{|c|c|c|c|c|c|c|c|c|}
\hline \multirow[b]{2}{*}{ Study or Subgroup } & \multicolumn{2}{|c|}{ Home } & \multicolumn{2}{|c|}{ Clinic } & \multirow[b]{2}{*}{ Weight } & \multirow{2}{*}{$\begin{array}{c}\text { Risk Ratio } \\
\text { M-H, Fixed, } 95 \% \mathrm{Cl}\end{array}$} & \multirow{2}{*}{$\begin{array}{c}\text { Risk Ratio } \\
\text { M-H, Fixed, 95\% Cl }\end{array}$} & Risk of Bias \\
\hline & Events & Total & Events & Total & & & & A B C D E F G \\
\hline Graseck 2010 & 3 & 268 & 5 & 280 & $9.6 \%$ & $0.63[0.15,2.60]$ & & \\
\hline Lippman 2007 & 38 & 410 & 43 & 408 & $84.5 \%$ & $0.88[0.58,1.33]$ & & \\
\hline Reagan 2012 & 4 & 100 & 3 & 100 & $5.9 \%$ & $1.33[0.31,5.81]$ & & \\
\hline Total $(95 \% \mathrm{Cl})$ & & 778 & & 788 & $100.0 \%$ & $0.88[0.60,1.29]$ & & \\
\hline Total events & 45 & & 51 & & & & & \\
\hline $\begin{array}{l}\text { Heterogeneity: } \mathrm{Chi}^{2}= \\
\text { Test for overall effect }\end{array}$ & $\begin{array}{l}0.52, \mathrm{df}= \\
Z=0.64(\end{array}$ & $\begin{array}{l}2(P= \\
P=0.5\end{array}$ & $\begin{array}{l}0.77) ;\left.\right|^{2}= \\
\text { 2) }\end{array}$ & $0 \%$ & & & 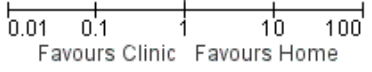 & \\
\hline $\begin{array}{l}\text { Risk of bias leqend } \\
\text { (A) Random sequen } \\
\text { (B) Allocation concea } \\
\text { (C) Blinding of partici } \\
\text { (D) Blinding of outcor } \\
\text { (E) Incomplete outco } \\
\text { (F) Selective reportin } \\
\text { (G) Other bias }\end{array}$ & $\begin{array}{l}\text { e generat } \\
\text { ment (sel } \\
\text { ants and } \\
\text { le assess } \\
\text { pe data (a } \\
\text { (reporting }\end{array}$ & $\begin{array}{l}\text { tion (se } \\
\text { lection } \\
\text { person } \\
\text { sment ( } \\
\text { attrition } \\
\mathrm{g} \text { bias) }\end{array}$ & $\begin{array}{l}\text { lection bi } \\
\text { bias) } \\
\text { nnel (perfo } \\
\text { (detection } \\
\text { bias): Sho }\end{array}$ & $\begin{array}{l}\text { ias) } \\
\text { ormano } \\
\text { bit-tern }\end{array}$ & $\begin{array}{l}\text { ce bias) } \\
\text { Subjectiv } \\
\text { m outcom }\end{array}$ & $\begin{array}{l}\text { ve outcomes } \\
\text { les }\end{array}$ & & \\
\hline
\end{tabular}

\section{Secondary outcomes}

\subsection{Proportion of individuals tested}

All included studies evaluated the proportion of individuals tested. The proportions of participants tested varied widely between studies. Amongst participants assigned to home-based specimen collection, uptake ranged from $30 \%$ (95\% CI $26 \%$ to $33 \%, 189$ / 639) of women invited to be re-tested after treatment for CT or NG in the USA (Xu 2011, RR 1.61, 95\% CI 1.32 to 1.97 ) to $96 \%$ (95\% CI 93\% to $98 \%, 393 / 410$ ) of women invited to have a first time test for CT, NG or TV in Brazil (Lippman 2007, RR 0.99 95\% CI 0.97 to 1.02 ). Amongst participants assigned to clinicbased specimen collection, uptake ranged from $6 \%$ of high school students who were advised to have a CT test at a physician's office in Denmark (Ostergaard 1998); to $97 \%$ (95\% CI $94 \%$ to $98 \%$, $394 / 408$ ) invited to have a first time test for CT, NG or TV in Brazil (Lippman 2007).

There was substantial heterogeneity between the results of individual studies and we did not pool the results (participants = 10479; studies $=10 ; \mathrm{I}^{2}=100 \%$, tau 2.15; Analysis 1.2; Figure 5) . In eight of 10 studies the proportion of participants tested was higher with home-collected specimens than clinic-collected specimens (Andersen 1998; Ostergaard 1998; Ostergaard 2003; Cook 2007; Graseck 2010; Xu 2011; Reagan 2012; Götz 2013); and in two studies there was no difference in test uptake (Jones 2007; Lippman 2007). The largest difference in uptake was in the trial by Ostergaard 1998 (RR 20.55, 95\% CI 15.08 to 28.00). In a sensitivity analysis that excluded this study, heterogeneity remained 
extremely high $\left(\mathrm{I}^{2}=99 \%\right.$, tau 0.4$)$ with a RR from random effects meta-analysis of 1.56 (95\% CI 1.03 to 2.38). We judged the quality of evidence as low as a result of high risk of selection and attrition bias, and inconsistency in the included studies (Summary of findings for the main comparison).

Figure 5. Forest plot of comparison: I Home-based vs clinic-based specimen collection for CT and NG, outcome: I.2 Proportion of individuals tested.

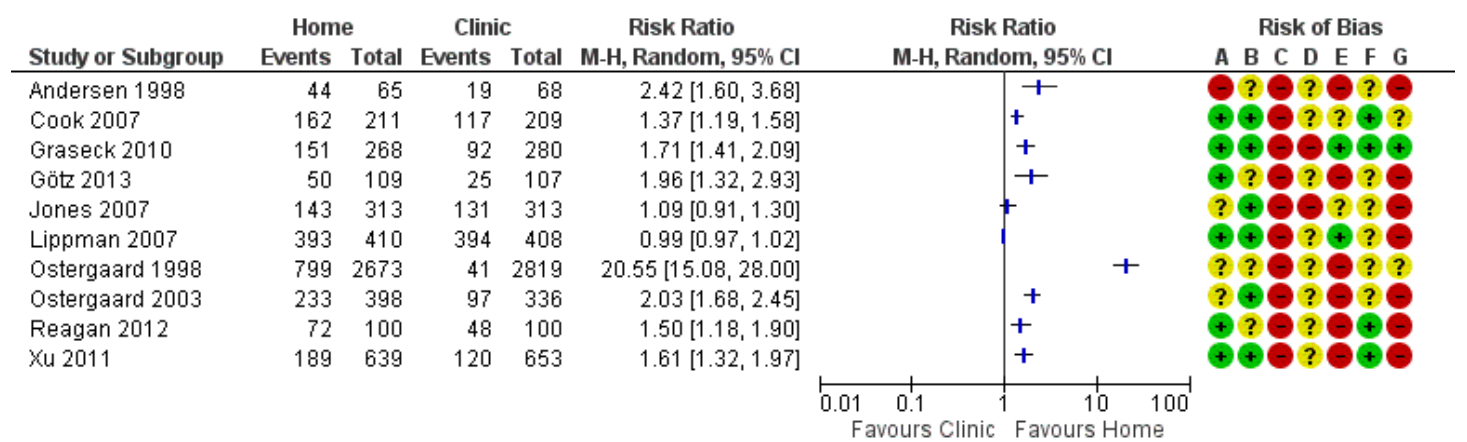

\footnotetext{
Risk of bias legend

(A) Random sequence generation (selection bias)

(B) Allocation concealment (selection bias)

(C) Blinding of participants and personnel (performance bias)

(D) Blinding of outcome assessment (detection bias): Subjective outcomes

(E) Incomplete outcome data (attrition bias): Short-term outcomes

(F) Selective reporting (reporting bias)

(G) Other bias
}

\subsection{Proportion of individual tested grouped by sex}

In both women and men, a higher proportion of participants returned specimens in the home-based than clinic-based group (Analysis 1.3). Between-trial heterogeneity remained high, however, in both women $\left(\mathrm{I}^{2}=100 \%\right.$, tau 2.04$)$ and men $\left(\mathrm{I}^{2}=95 \%\right.$, tau 0.94). Using meta-regression, there was inconclusive evidence that the effect size differed between women and men (RRR 0.72 . $95 \%$ CI 0.40 to $1.31, \mathrm{I}^{2}=93 \%$ ).

\subsection{Proportion of individual tested grouped by STI risk}

When trials were stratified according to the risk of participants being infected with an STI (high or low), more participants in the home-based group than in the clinic-based group returned specimens in both subgroups (Analysis 1.4). Between-trial heterogeneity remained high (high risk participants $\mathrm{I}^{2}=75 \%$, tau 5.93; low risk participants $\mathrm{I}^{2}=100 \%$, tau 0.04 ). Using meta-regression, there was no difference in the effect size between groups (high risk versus low risk RRR 0.88 , 95\% CI 0.27 to 2.85 , I² = 98\%).
1.5 Proportion of individual tested grouped by method of returning specimens

There was only one trial in which participants returned homecollected specimens to the clinic in person. Amongst trials in which home-collected specimens were returned by post, heterogeneity remained extreme ( $\mathrm{I}^{2}=100 \%$, tau 0.64; Analysis 1.5$)$. In metaregression, the effect sizes differed somewhat (RRR 0.47, 95\% CI 0.07 to $2.96, \mathrm{I}^{2}=96 \%$ ), but confidence intervals were very wide.

\subsection{Proportion of individual tested grouped by use of reminders}

When trials were stratified according to the stated use of reminders or not, more participants In the home-based group than in the clinic-based group returned specimens in both subgroups (Analysis 1.6). In two trials that did not use reminders, the findings were statistically consistent (RR 1.62 , 95\% CI 1.39 to 1.89 ; participants $=748 ; \mathrm{I}^{2}=0 \%$, tau 0.00$)$. In five trials that used reminders, heterogeneity remained high $\left(\mathrm{I}^{2}=98 \%\right.$, tau 0.23$)$. In meta-regres- 
sion, there was inconclusive evidence that the effect sizes differed between trials that used reminders versus trials that did not (RRR $0.81,95 \%$ CI 0.48 to $\left.1.37, \mathrm{I}^{2}=90 \%\right)$.

\subsection{Positive test prevalence}

Nine studies reported numbers of positive test results as a proportion of participants tested (Andersen 1998; Ostergaard 1998; Ostergaard 2003; Jones 2007; Lippman 2007; Graseck 2010; Xu 2011; Reagan 2012; Götz 2013). Cook 2007 reported rates of positive tests per 100 woman-years of follow-up (20.4 for homecollected specimens versus 24.1 for clinic-collected specimens, $\mathrm{P}$ $=0.28$ ) and we did not combine these with the outcomes reported as proportions.

The proportions of positive test results varied between trials. The lowest proportions were in trials that enrolled participants from a cohort study of contraceptive practices in women in the US (
Graseck 2010, 2.3\%); high schools in Denmark (Ostergaard 1998, $4.4 \%$ ); and community-based efforts with men in the US (Reagan 2012, 5.8\%). The highest proportions were in patients who had sex partners with CT or NG (Andersen 1998, 30\%; Ostergaard 2003, 43\%).

Meta-analysis of nine trials showed a lower proportion of positive CT or NG test results with home-based (240/2074, 11.6\%) than with clinic-based $(179 / 967,18.5 \%)$ specimen collection (RR $0.72,95 \%$ CI 0.61 to 0.86 ; participants $=3041$; studies $=9$; $\mathrm{I}^{2}$ = 0\%, tau 0.00); Analysis 1.7; Figure 6). We used a fixed-effect model, owing to the low between-study heterogeneity $\left(\mathrm{I}^{2}<50 \%\right)$. A sensitivity analysis that excluded the cluster-randomized trial by Ostergaard 1998 did not change the results (RR 0.73, 95\% CI 0.61 to 0.87 ; participants $=2201 ;$ studies $=8 ; \mathrm{I}^{2}=0 \%$, tau 0.00 ) We judged the quality of evidence as moderate as a result of high risk of biases in the included studies (Summary of findings for the main comparison).

Figure 6. Forest plot of comparison: I Home-based vs clinic-based specimen collection for CT and NG, outcome: I.7 Positive test prevalence.

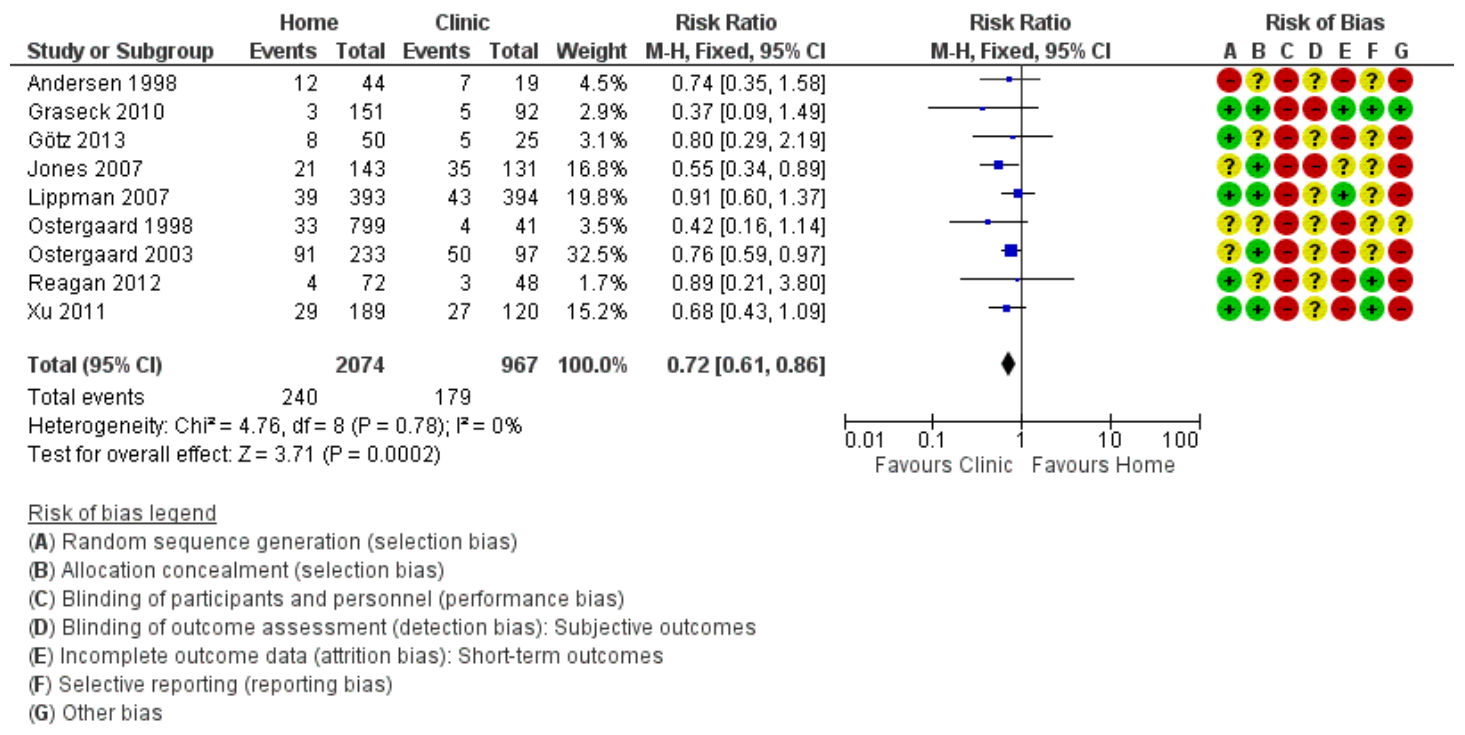

\subsection{Proportion of infections treated}

Only three of the trials included in the analysis of primary outcomes clearly stated that patients with positive test results were treated. Lippman 2007 reported that all but one woman in the home group was not treated. We did not perform a meta-analysis to analyse these results.

\subsection{Process outcomes}

We found four studies that addressed issues related to adherence and compliance (Jones 2007; Lippman 2007; Graseck 2010; Reagan 2012). Reagan 2012 reported on barriers to testing during a follow-up survey with 129 men. They found that $16 \%$ did not complete the testing due to lack of health insurance, $12 \%$ because 
of the cost of screening, and $9 \%$ because of difficulties with transportation to the clinic. Participants also reported the following subjective concerns: inconvenience of screening, 7\%; bad experience with previous STI test, $5 \%$; concern about the safety of the test, $5 \%$; concern about privacy if the test result were positive, $5 \%$; and disapproval by family members about testing, $2 \%$. Graseck 2010 reported, in a survey with 207 women, that the main reason for not completing the test was "forgot" in $49 \%$ in the home-based group and $24 \%$ in the clinic group.

Feasibility and acceptability were evaluated by Jones 2007 and Lippman 2007. These two studies shared almost the same protocol, but the trial was performed in different countries. Lippman 2007 analysed data from 787 women that answered a questionnaire in Brazil. Women collected their own samples in both homeand clinic-based groups and $96 \%$ of women in both groups found self-sample collection to be comfortable and easy. A survey that included 244 women in the study by Jones 2007 in South Africa found that $86 \%$ of women in the home-based group and $96 \%$ in clinic-based group found self-sample collection very easy. Acceptability, evaluated as feeling pain during sampling, was reported in $17 \%$ of home-based group and $12 \%$ of the clinic-based group.

\subsection{Economic outcomes}

Smith 2007 examined the direct and indirect costs associated with home- and clinic-based specimen collection for CT and NG, using data gathered in the trial by Cook 2007. The outcome was the number of completed tests per participant. Direct costs were $\$ 49$ per test in clinic-based group and indirect costs were $\$ 62$ per test, while in the home-based group they reported that the cost was $\$ 25$ per test.

\section{Subgroup analysis and investigation of heterogeneity}

We did not conduct subgroup analyses or sensitivity analyses for the primary outcome because only three trials provided results. The findings of these trials were statistically consistent.

The findings of subgroup analyses for the outcome "proportion of individuals tested" are reported in paragraphs 1.3 to 1.6 , with the overall analysis of this secondary outcome .

We did not perform subgroup analyses for "notification and treatment at clinic or sent to home", "pregnant women" and "adolescents" because none of the included trials reported information about these subgroups.

\section{ISCUSSION}

\section{Summary of main results}

Ten RCTs including 10,479 participants (7341 women and 3138 men) fulfilled the inclusion criteria and were included. Three trials (1566 participants) assessed the primary outcome. There was no evidence of a difference in index case management between home-based and clinic-based specimen collection as part of a case management strategy for Chlamydia trachomatis (CT) or Neisseria gonorrhoeae (NG). We judged the level of evidence as moderate. Harms of testing, which was a primary outcome, were not evaluated in any trial.

All included trials compared the proportion of individuals tested. Between-trial heterogeneity was very high so we did not pool the results, but uptake of testing was higher with home-collected than with clinic-collected specimens in eight of 10 included trials. Heterogeneity was not explained by sex of the patient, level of STI risk, procedure for returning specimens or use of reminders. We judged the risk of bias for this secondary outcome as high and the quality of evidence as low.

Nine trials (3041 participants) compared the positive test prevalence and there was evidence of a lower proportion of positive tests in participants assigned to home-based specimen collection. We judged the risk of bias for this secondary outcome as high and the quality of evidence as moderate.

Four trials evaluated outcomes about adherence and compliance with the use of home-collected specimens. Self-sampling was reported to be comfortable and easy both at home or in a clinic.

\section{Overall completeness and applicability of evidence}

The evidence that we found about the use of home-collected specimens to improve the outcomes of case management for CT and NG infections was incomplete for two reasons. First, owing to an absence of studies, we could not assess the effect of the intervention on the complete pathway for comprehensive case management (UNAIDS 1999). Successful case management for bacterial STIs does not stop with providing treatment because of the risk to the patient of re-infection by a known but untreated sex partner. A biological outcome, such as testing negative for CT or NG 12 months after treatment would be much more robust as an effectiveness outcome, but none of the RCTs that we assessed reported on sexual partner management or repeated tests 12 months after the intervention. Second, only three of the 10 included trials reported on the intermediate outcome that we chose as our primary outcome. Even so, the RCTs included did not specify the antibiotics used for treatment.

The body of evidence about the use of home-collected specimens for STI testing comprises mainly RCTs that measured only the proportion of people that returned a specimen for testing. Test uptake is not a clinically relevant outcome because it does not give any information about the presence of an STI or whether the infection was successfully treated. Secondary outcomes like test uptake and the positive test results help to interpret the primary 
outcome. Test uptake was extremely heterogeneous between the trials, which used a wide variety of different methods to enroll participants and follow them up. We could not explain the heterogeneity in any of the subgroup analyses. Several trials had small sample sizes, which could have contributed to the heterogeneity (IntHout 2015).

Evidence about the primary outcome was restricted to people who did not have symptoms of, or specific risk factors for, STI. The three RCTs enrolled women taking part in another research study (Graseck 2010), women attending clinics providing maternal and child health services (Lippman 2007), and men contacted through word of mouth and community outreach (Reagan 2012). The majority of participants enrolled in the other included trials were people at high risk of CT or NG because they themselves have recently been treated or have an infected sexual partner (Andersen 1998; Ostergaard 2003; Cook 2007; Xu 2011; Götz 2013).

\section{Quality of the evidence}

In RCTs exploring the outcomes of home-based specimen collection, where both personnel and participants know which arm of the trial they are in, adequate allocation concealment is an important procedure to minimize selection bias. Reporting of allocation concealment was adequate in six of 10 included studies. High levels of follow-up are also important; all but one included trial had more than $20 \%$ missing data. The study that included the larger number of individuals was a cluster RCT that was analysed without taking into account variability within and between clusters. Only one study reported clear blinding of outcome assessors. No trial had a high risk of selective reporting bias.

We assessed the quality of evidence provided by the three studies reporting the primary outcome as moderate, due to study limitations. Trials reporting on positive test prevalence showed moderate-quality evidence that clinic-based specimen collection increased more than home-based specimen collection the number of participants diagnosed, and we downgraded the quality of evidence due to study limitations (Summary of findings for the main comparison).

\section{Potential biases in the review process}

There is a risk of small-study biases in this review. We performed an extensive and comprehensive search of electronic databases with no language restrictions to identify all published and unpublished trials. Nevertheless, we found only three trials that allowed us to assess the primary outcome. There were too few trials to draw a funnel plot. We tried to contact trial authors to obtain additional information but were not successful. During the review process three authors carried out the study selection, eligibility assessment and data extraction to minimize bias in the data collection.

\section{Agreements and disagreements with other studies or reviews}

Odesanmi 2013 reviewed RCTs comparing home-based and clinic-based specimen collection in women. They found six trials, all of which we included in this review. In contrast to our review, the authors considered uptake of testing as an effectiveness outcome. The authors also found high levels of heterogeneity overall. In a subgroup analysis of two trials with outcome data derived from a combination of self-report and medical records they found reduced heterogeneity and reported an increase in the uptake of testing with home-based specimen collection (Jones 2007; Graseck 2010). We identified two additional trials that included women (Ostergaard 2003; Götz 2013), but one was published after the end of the search period (Götz 2013).

\section{A U THORS, CONCLUSIONS}

\section{Implications for practice}

The review findings are compatible with home-based and clinicbased specimen collection resulting in similar levels of patients being treated for CT or NG infection. Home-based specimen collection appears to encourage more people to be tested, but the people attending clinics who undergo testing are more likely to have an STI. The additional yield of tests from those who collect specimens at home might therefore include people at lower risk of an STI, whilst people who attend the clinic are those who are infected. These opposing effects probably explain why home-based and clinic-based specimen collection resulted in similar rates of completed testing and treatment in the few trials that documented this information. The review does not allow any conclusions about microbiological cure, partner management or re-infection. The safety of home-based specimen collection compared with clinicbased specimen collection has not been evaluated.

\section{Implications for research}

Test uptake is not a clinically relevant primary outcome for trials because it does not capture the effects of testing strategies on adequate treatment, follow-up and sexual partner management. Future RCTs to assess the effectiveness of home-based specimen collection should be designed to measure biological outcomes of STI case management, such as proportion of participants with negative tests for the relevant STI at follow-up.

\section{A C K NOW LEDGEMENTS}

Dr. Bracho AC revised the first draft of the protocol, providing a clinical perspective. Lies Wijnterp, PhD Candidate in Spanish/So- 
ciology of Literature at Radboud University Nijmegen, corrected

the protocol's English version.

\section{RE FE R E N C E S}

\section{References to studies included in this review}

Andersen 1998 \{published data only\}

Andersen B, Ostergaard L, Moller JK, Olesen F. Home sampling versus conventional contact tracing for detecting Chlamydia trachomatis infection in male partners of infected women: randomised study. BMJ (Clinical research ed) 1998;316(7128):350-1. [PUBMED: 9487169]

Cook 2007 \{published data only\} Cook RL, Ostergaard L, Hillier SL, Murray PJ, Chang CC, Comer DM, et al. Home screening for sexually transmitted diseases in high-risk young women: randomised controlled trial. Sexually Transmitted Infections 2007;83(4):286-91. [PUBMED: 17301105]

Götz 2013 \{published data only\} Götz HM, Wolfers MEG, Luijendijk A, van den Broek IVF. Retesting for genital Chlamydia trachomatis among visitors of a sexually transmitted infections clinic: Randomized intervention trial of home-versus clinic-based recall. $B M C$ Infectious Diseases 2013;13:239. [PUBMED: 23705624]

Graseck 2010 \{published data only\}

Graseck AS, Secura GM, Allsworth JE, Madden T, Peipert JF. Home compared with clinic-based screening for sexually transmitted infections: A randomized controlled trial. Obstetrics and Gynecology 2010;116(6):1311-8. [PUBMED: 21099596]

Jones 2007 \{published data only\}

Jones HE, Altini L, de Kock A, Young T, van de Wijgert JH. Home-based versus clinic-based self-sampling and testing for sexually transmitted infections in Gugulethu, South Africa: randomised controlled trial. Sexually Transmitted Infections 2007;83(7):552-7. [PUBMED: 17901084]

Lippman 2007 \{published data only\} Lippman SA, Jones HE, Luppi CG, Pinho AA, Veras MAMS, Van De Wijgert JHHM. Home-based selfsampling and self-testing for sexually transmitted infections: Acceptable and feasible alternatives to providerbased screening in low-income women in Sao Paulo, Brazil. Sexually Transmitted Diseases 2007;34(7):421-8. [PUBMED: 17091118]

Ostergaard 1998 \{published data only\} Ostergaard L, Andersen B, Olesen F, Moller JK. Efficacy of home sampling for screening of Chlamydia trachomatis: randomised study. BMJ (Clinical research ed) 1998;317 (7150):26-7. [PUBMED: 9651263]

Ostergaard 2003 \{published data only\} Ostergaard L, Andersen B, Moller JK, Olesen F, Worm AM. Managing partners of people diagnosed with Chlamydia trachomatis: A comparison of two partner testing methods.
Sexually Transmitted Infections 2003;79(5):358-62. [PUBMED: 14573827]

Reagan 2012 \{published data only\}

Reagan MM, Xu H, Shih SL, Secura GM, Peipert JF. A randomized trial of home versus clinic-based sexually transmitted disease screening among men. Sexually Transmitted Diseases 2012;39(11):842-7. [PUBMED: 23064532]

Xu 2011 \{published data only\}

Xu F, Stoner BP, Taylor SN, Mena L, Tian LH, Papp J, et al. Use of home-obtained vaginal swabs to facilitate rescreening for Chlamydia trachomatis infections: Two randomized controlled trials. Obstetrics and Gynecology 2011;118(2 PART 1):231-9. [PUBMED: 21775837]

\section{References to studies excluded from this review}

Andersen 2002 \{published data only\} Andersen B, Olesen F, Moller JK, Ostergaard L. Populationbased strategies for outreach screening of urogenital Chlamydia trachomatis infections: a randomized, controlled trial. Journal of Infectious Diseases 2002;185(2):252-8. [PUBMED: 11807700]

Andersen 2011 \{published data only\} Andersen B, Van Valkengoed I, Sokolowski I, Moller JK, Ostergaard L, Olesen F. Impact of intensified testing for urogenital Chlamydia trachomatis infections: A randomised study with 9-year follow-up. Sexually Transmitted Infections 2011;87(2):156-61. [PUBMED: 21097811]

Buhrer-Skinner 2011 \{published data only\} Buhrer-Skinner M, Muller R, Buettner PG, Gordon R, Debattista J. Improving Chlamydia trachomatis retesting rates by mailed self-collection kit. Sexual Health 2011;8(2): 248-50. [PUBMED: 21592441]

Emmerton 2011 \{published data only\} Emmerton L, Buhrer Skinner M, Gardiner E, Nissen L, Debattista J. A trial of the distribution of chlamydia selfcollection postal specimen kits from Australian community pharmacies. Sexual Health 2011;8(1):130-2. [PUBMED: 21371398]

\section{Falk 2014 \{published data only\}}

Falk L, Hegic S, Wilson D, Wirehn A-B. Home-sampling as a tool in the context of Chlamydia trachomatis partner notification: a randomized controlled trial. Acta DermatoVenereologica 2014;94(1):72-4. [PUBMED: 23807656]

Gray 1998 \{published data only\} Gray RH, Wawer MJ, Girdner J, Sewankambo NK, Serwadda D, Meehan M, et al. Use of self-collected vaginal swabs for detection of Chlamydia trachomatis infection. 
Sexually Transmitted Diseases 1998;25(8):450. [PUBMED: 9773442]

Klovstad 2013 \{published data only\}

Klovstad H, Natas O, Tverdal A, Aavitsland P. Systematic screening with information and home sampling for genital Chlamydia trachomatis infections in young men and women in Norway: A randomized controlled trial. $B M C$ Infectious Diseases 2013;13:30. [PUBMED: 23343391]

Ostergaard 1999 \{published data only\}

Ostergaard LJ, Andersen BS, Olesen F, Moller JK. Detection of Chlamydia trachomatis infection among young people. The effect of home-sampling and mailing the samples. Ugeskr Laeger 1999;161(32):4514-8. [PUBMED: 10477967]

Ostergaard 2000 \{published data only\}

Ostergaard L, Andersen B, Moller JK, Olesen F. Home sampling versus conventional swab sampling for screening of Chlamydia trachomatis in women: A cluster-randomized 1-year follow-up study. Clinical Infectious Diseases 2000;31 (4):951-7. [PUBMED: 11049776]

Scholes 2007 \{published data only\}

Scholes D, Heidrich FE, Yarbro P, Lindenbaum JE, Marrazzo JM. Population-based outreach for chlamydia screening in men: Results from a randomized trial. Sexually Transmitted Diseases 2007;34(11):837-9. [PUBMED: 17538514]

Sparks 2004 \{published data only\} Sparks R, Helmers JR, Handsfield HH, Totten PA, Holmes KK, Wroblewski JK, et al. Rescreening for gonorrhea and chlamydial infection through the mail: a randomized trial. Sexually Transmitted Diseases 2004;31(2):113-6. [PUBMED: 14743074]

Van Valkengoed 2002 \{published data only\} Van Valkengoed IGM, Morre SA, Meijer C, Van Den Brule AJC, Boeke AJP. Do questions on sexual behaviour and the method of sample collection affect participation in a screening programme for asymptomatic Chlamydia trachomatis infections in primary care?. International Journal of STD \& AIDS 2002;13(1):36-8. [PUBMED: 11802928]

\section{References to studies awaiting assessment}

Apoola 2009 \{published data only\}

Apoola A, Beardsley J. Does the addition of a urine testing kit to use of contact slips increase the partner notification rates for genital chlamydial infection?. International Journal of STD and AIDS 2009;20(11):775-7. [PUBMED: 19833688]

\section{References to ongoing studies}

De Barbeyrac 2013 \{published data only\}

De Barbeyrac B, Rahib D, De Diego S, Le Roy C, Bebear C, Lydie N. Internet testing for chlamydia trachomatis in France in 2012. Sexually Transmitted
Infections 2013;89(Suppl 1):A155-A156. [DOI: 10.1136/ sextrans-2013-051184.0485]

Smith 2014 \{published data only\}

Smith KS, Hocking JS, Chen M, Fairley CK, McNulty

A, Read P, et al. Rationale and design of REACT: A randomised controlled trial assessing the effectiveness of home-collection to increase chlamydia retesting and detect repeat positive tests. BMC Infectious Diseases 2014;14:223. [PUBMED: 24758169]

\section{Additional references}

Blandford 2006

Blandford JM, Gift TL. Productivity losses attributable to untreated chlamydial infection and associated pelvic inflammatory disease in reproductive-aged women. Sexually Transmitted Diseases 2006;33(10 Suppl):S117-21. [PUBMED: 17003678]

Carey 2010

Carey AJ, Beagley KW. Chlamydia trachomatis, a hidden epidemic: effects on female reproduction and options for treatment. American Journal of Reproductive Immunology 2010;63(6):576-86. [PUBMED: 20192953]

\section{Chernesky 2005}

Chernesky MA, Hook EW3, Martin DH, Lane J, Johnson $\mathrm{R}$, Jordan JA, et al. Women find it easy and prefer to collect their own vaginal swabs to diagnose Chlamydia trachomatis or Neisseria gonorrhoeae infections. Sexually Transmitted Diseases 2005;32(12):729-33. [PUBMED: 16314768]

\section{Chesson 2008}

Chesson HW, Collins D, Koski K. Formulas for estimating the costs averted by sexually transmitted infection (STI) prevention programs in the United States. Cost Effectiveness and Resource Allocation 2008;6:10. [DOI: 10.1186/ 1478-7547-6-10]

Deeks 2001

Deeks JJ, Altman DG, Bradburn MJ. Statistical Methods for Examining Heterogeneity and Combining Results from Several Studies in Meta-Analysis. In: M. Egger, G. D. Smith, D. G. Altman editor(s). Systematic Reviews in Health Care: Meta-Analysis in Context. Second Edition. London, UK: BMJ Publishing Group, 2001. [DOI: 10.1002/ 9780470693926.ch15]

\section{Gaydos 2004}

Gaydos CA, Theodore M, Dalesio N, Wood BJ, Quinn TC. Comparison of three nucleic acid amplification tests for detection of Chlamydia trachomatis in urine specimens. Journal of Clinical Microbiology 2004;42(7):3041-5. [PUBMED: 15243057]

\section{Gaydos 2006}

Gaydos CA, Rizzo-Price PA, Barnes M, Dwyer K, Wood BJ, Hogan MT. The use of focus groups to design an internet-based program for chlamydia screening with selfadministered vaginal swabs: what women want. Sexual Health 2006;3(4):209-15. [PUBMED: 17112429] 


\section{Graseck 2011}

Graseck AS, Shih SL, Peipert JF. Home versus clinicbased specimen collection for Chlamydia trachomatis and Neisseria gonorrhoeae. Expert Review of Anti-infective Therapy 2011;9(2):183-94. [PUBMED: 21342066]

Götz 2006

Götz HM, van Bergen JE, Veldhuijzen IK, Hoebe CJ, Broer $\mathrm{J}$, Coenen AJ, et al. Lessons learned from a population-based chlamydia screening pilot. International Journal of STD \& AIDS 2006;17(12):826-30. [PUBMED: 17212860]

Higgins 2003

Higgins JPT, Thompson SG, Deeks JJ, Altman DG. Measuring inconsistency in meta-analyses. BMJ 2003;327: 557-60. [PUBMED: 12958120]

Higgins 2011

Higgins JPT, Green S (editors). Cochrane Handbook for Systematic Reviews of Interventions Version 5.1.0 [updated March 2011]. The Cochrane Collaboration, 2011. Available from www.cochrane-handbook.org.

\section{Hobbs 2008}

Hobbs MM, van der Pol B, Totten P, Gaydos CA, Wald

A, Warren T, et al. From the NIH: proceedings of a workshop on the importance of self-obtained vaginal specimens for detection of sexually transmitted infections. Sexually Transmitted Diseases 2008;35(1):8-13. [PUBMED: 18157061]

IntHout 2015

IntHout J, Ioannidis JP, Borm GF, Goeman JJ. Small studies are more heterogeneous than large ones: a meta-metaanalysis. Journal of clinical epidemiology 2015;68(8):860-9. [PUBMED: 25959635]

Low 2006

Low N, Broutet N, Adu-Sarkodie Y, Barton P, Hossain M, Hawkes S. Global control of sexually transmitted infections. Lancet 2006;368(9551):2001-16. [PUBMED: 17141708]

Low 2007

Low N. Screening programmes for chlamydial infection: when will we ever learn?. BMJ (Clinical research ed.) 2007; 334(7596):725-8. [PUBMED: 17413173]

\section{Macleod 2005}

Macleod J, Salisbury C, Low N, McCarthy A, Sterne JA, Holloway A, et al. Coverage and uptake of systematic postal screening for genital Chlamydia trachomatis and prevalence of infection in the United Kingdom general population: cross sectional study. BMJ (Clinical research ed.) 2005;330 (7497):940. [PUBMED: 15809231]

\section{Manhart 2005}

Manhart LE, Holmes KK. Randomized controlled trials of individual-level, population-level, and multilevel interventions for preventing sexually transmitted infections: what has worked?. Journal of Infectious Diseases 2005;191 Suppl 1:S7-24. [PUBMED: 15627233]

\section{Masek 2009}

Masek BJ, Arora N, Quinn N, Aumakhan B, Holden J, Hardick A, et al. Performance of three nucleic acid amplification tests for detection of Chlamydia trachomatis and Neisseria gonorrhoeae by use of self-collected vaginal swabs obtained via an Internet-based screening program. Journal of Clinical Microbiology 2009;47(6):1663-7. [PUBMED: 19386838]

Mayaud 2004

Mayaud P, Mabey D. Approaches to the control of sexually transmitted infections in developing countries: old problems and modern challenges. Sexually Transmitted Infections 2004;80(3):174-82. [PUBMED: 15169997]

Mehta 2002

Mehta SD, Bishai D, Howell MR, Rothman RE, Quinn TC, Zenilman JM. Cost-effectiveness of five strategies for gonorrhea and chlamydia control among female and male emergency department patients. Sexually Transmitted Diseases 2002;29(2):83-91. [PUBMED: 11818893]

\section{Meyers 2008}

Meyers D, Wolff T, Gregory K, Marion L, Moyer V, Nelson $\mathrm{H}$, et al. USPSTF recommendations for STI screening. American Family Physician 2008;77(6):819-24. [PUBMED: 18386598]

\section{Novak 2006}

Novak DP, Karlsson RB. Simplifying chlamydia testing: an innovative Chlamydia trachomatis testing approach using the internet and a home sampling strategy: population based study. SexuallyTransmitted Infections 2006;82(2):1427; discussion 152-3. [PUBMED: 16581742]

Núñez-Forero 2012

Núñez-Forero, Moyano LF, Angel-Müller E, RodríguezA, Ruiz-Parra AI, Tolosa JE, et al. Diagnostic accuracy of rapid tests for C. Trachomatis, N. Gonorrhoeae and Syphilis at the point of care in women with symptoms of lower genital tract infection. International Journal of Gynaecology and Obstetrics 2012;119(S3):S350. [DOI: 10.1016/ S0020-7292(12)60695-X]

\section{Odesanmi 2013}

Odesanmi TY, Wasti SP, Odesanmi OS, Adegbola O, Oguntuase OO, Mahmood S. Comparative effectiveness and acceptability of home-based and clinic-based sampling methods for sexually transmissible infections screening in females aged 14-50 years: A systematic review and metaanalysis. Sexual Health 2013;10(6):559-69. [PUBMED: 24160747]

\section{Rager 2001}

Rager KM, Biro FM. Techniques of testing for sexually transmitted diseases. Current Women's Health Reports 2001; 1(2):111-5. [PUBMED: 12112957]

RevMan

The Nordic Cochrane Centre, The Cochrane Collaboration. Review Manager (RevMan). 5.3. Copenhagen: The Nordic Cochrane Centre, The Cochrane Collaboration, 2014.

\section{Schünemann 2011a}

Schünemann HJ, Oxman AD, Higgins JPT, Vist GE, Glasziou P, Guyatt GH. Chapter 11: Presenting results and 'Summary of findings' tables. In: Higgins JPT, Green 
S editor(s). Cochrane Handbook for Systematic Reviews of Interventions Version 5.1.0 (updated March 2011). The Cochrane Collaboration, 2011.

\section{Schünemann 2011b}

Schünemann HJ, Oxman AD, Vist GE, Higgins JPT, Deeks JJ, Glasziou P, et al. Chapter 12: Interpreting results and drawing conclusions. In: Higgins JPT, Green S editor(s). Cochrane Handbook for Systematic Reviews of Interventions Version 5.1.0 (updated March 2011). The Cochrane Collaboration, 2011.

\section{Scott 2007}

Scott Lamontagne D, Baster K, Emmett L, Nichols T, Randall S, McLean L, et al. Incidence and reinfection rates of genital chlamydial infection among women aged 1624 years attending general practice, family planning and genitourinary medicine clinics in England: a prospective cohort study by the Chlamydia Recall Study Advisory Group. Sexually Transmitted Infections 2007;83(4): 292-303. [PUBMED: 17050567]

\section{Shih 2011}

Shih SL, Graseck AS, Secura GM, Peipert JF. Screening for sexually transmitted infections at home or in the clinic?. Current Opinion in Infectious Diseases 2011;24(1):78-84. [PUBMED: 21124216]

\section{Smith 2007}

Smith KJ, Cook RL, Ness RB. Cost comparisons between home- and clinic-based testing for sexually transmitted diseases in high-risk young women. Infectious Diseases in Obstetrics and Gynecology 2007;2007:62467. [PUBMED: 18273404]

Stata

StataCorp LP. Stata Statistical Software: Release 13. College Station, TX: StataCorp LP, 2013.

Ukoumunne 1999

Ukoumunne OC, Gulliford MC, Chinn S, Sterne JA, Burney PG. Methods for evaluating area-wide and organisation-based interventions in health and health care: a systematic review. Health Technology Assessment 1999;3(5): iii-92. [PUBMED: 10982317]

\section{UNAIDS 1999}

UNAIDS, WHO. Sexually transmitted diseases: policies and principles for prevention and care. UNAIDS best practice collection. Key material 1999.

\section{USPSTF 2007}

USPSTF. Screening for chlamydial infection: U.S.

Preventive Services Task Force recommendation statement. Annals of Internal Medicine 2007;147(2):128-34.

[PUBMED: 17576996]

Van Bergen 2006

Van Bergen J, Gotz H, Richardus JH, Hoebe C, Broer J,

Coenen T. Prevalence of urogenital Chlamydia trachomatis infections in the Netherlands suggests selective screening approaches. Results from the PILOT CT Population Study. Drugs of Today 2006;42 Suppl A:25-33. [PUBMED: 16683041]

WHO 2004

WHO, Department of Reproductive Health and Research. Guidelines for the management of sexually transmitted infections. Geneva, Switzerland: World Health Organization 2004.

WHO 2005

WHO, Department of Reproductive Health and Research. Global strategy for the prevention and control of sexually transmitted infections 2006-2015. Breaking the chain of transmission. Geneva, Switzerland: World Health Organization 2005.

\section{WHO 2012}

World Health Organization. Global incidence and prevalence of selected curable sexually transmitted infections - 2008. Geneva, Switzerland: World Health Organization 2012.

\section{Workowski 2010}

Workowski KA, Berman S, Centers for Disease Control and Prevention (CDC). Sexually transmitted diseases treatment guidelines, 2010. MMWR Recommendations and Reports 2010 Dec 17;59 (RR-12):1-110. [PUBMED: 21160459]

\section{References to other published versions of this review}

\section{Fajardo-Bernal 2014}

Fajardo-Bernal L, Angel-Müller E, Aponte-Gonzalez J, Rincon C, Gaitán Hernando G, Low N. Home-based versus clinic-based management strategy for Chlamydia trachomatis and Neisseria gonorrhoeae. Cochrane Database of Systematic Reviews. John Wiley \& Sons, Ltd, 2014, issue 9. [DOI: 10.1002/14651858.CD011317; : CD011317]

* Indicates the major publication for the study 


\section{CHARACTERISTICS OF STUDIES}

\section{Characteristics of included studies [ordered by study ID]}

\section{Andersen 1998}

\begin{tabular}{|c|c|}
\hline Methods & $\begin{array}{l}\text { Setting: General practices in Aarhus, Denmark } \\
\text { Study design: Parallel two arms. No specific dates reported. } \\
\text { Sample size estimation a priori: No }\end{array}$ \\
\hline Participants & $\begin{array}{l}\text { Inclusion criteria } \\
\text { - Women } \\
\text { - CT positive } \\
\text { Exclusion criteria } \\
\text { - Not specified } \\
\text { Population } \\
\text { Mean age not reported } \\
96 \text { women with C. trachomatis were randomized, their } 133 \text { male sexual partners received } \\
\text { the interventions }\end{array}$ \\
\hline Interventions & $\begin{array}{l}\text { Home-based specimen collection for male sexual partners }(n=65) \\
\text { Index patients completed a questionnaire about numbers of sexual partners and contacted } \\
\text { their partners to collect first urine sample at home for CT test. Then they returned the } \\
\text { sample to laboratory in a prepaid envelope. } \\
\text { Clinical-based specimen collection for male sexual partners }(n=68) \\
\text { Not reported if index patients completed questionnaire. Index patients were given an } \\
\text { envelope containing a contact slip and a request to partner to visit his doctor for a urethral } \\
\text { swab sample for CT test. The doctor returned the sample to study laboratory in a prepaid } \\
\text { envelope }\end{array}$ \\
\hline
\end{tabular}

Outcomes

- Partners contacted (partners receiving a urine sample test kit or contact slip delivered by index patient)

- Partners tested (review of laboratory records) (44/65) (19/68)

- Partners testing CT positive (review of laboratory records) (12/44) (7/19) and time until testing (clinical records)

\begin{tabular}{lll}
\hline Notes & $\begin{array}{l}\text { Funding sources: “University of Aarhus, Denmark and Nycomed DAK” } \\
\text { Role of funder: Not reported. } \\
\text { Declarations of interest: None declared. } \\
\text { Not reported if partners testing CT positive were treated. Ethical approval was obtained. } \\
\text { Unclear whether consent was obtained } \\
\text { Number of identifier register: Not found. }\end{array}$ \\
\hline Risk of bias & & Support for judgement \\
\hline Bias & Authors' judgement & $\begin{array}{l}\text { Quote "Ninety six women with C tra- } \\
\text { chomatis infection seen in general prac- } \\
\text { tices in Aarhus County, Denmark, were }\end{array}$ \\
\hline $\begin{array}{l}\text { Random sequence generation (selection } \\
\text { bias) }\end{array}$ & High risk &
\end{tabular}


randomly divided according to their date of birth into an intervention group (45 patients) and a control group (51 patients)"

Allocation concealment (selection bias) Unclear risk

Blinding of participants and personnel High risk (performance bias)

All outcomes

Blinding of outcome assessment (detection Unclear risk

bias)

Subjective outcomes

Blinding of outcome assessment (detection Unclear risk bias)

Objective outcomes

Incomplete outcome data (attrition bias) High risk

Short-term outcomes

Incomplete outcome data (attrition bias) Unclear risk Long-term outcomes

Selective reporting (reporting bias) Unclear risk

High risk
Envelopes used for both groups but not stated if they appeared identical. No details on allocation concealment given in report

No blinding, the outcomes are likely to be influenced by lack of blinding

No subjective outcomes reported.

It is not reported whether the laboratory personnel or assessors were blinded
Intervention group sexual partners tested were 44/65, control group 19/68. More than $20 \%$ of participants were not tested and the missing data were not balanced in the groups

Only number of individuals not tested reported; however clearly information was not available to make a judgement

Outcomes reported in Methods section were reported in Results section. Protocol not available from 3 trial registries

Participants were sexual partners of CT positive patients.

Cook 2007

Methods

Setting: Community-based medical clinics and its neighbourhoods in Western Pennsylvania.

Study design: Parallel two arms. Enrolment between November 2000 and April 2003

Sample size estimation a priori: Yes.

Participants

\section{Inclusion criteria}

- Women

- Age 15 to 24 years

- Recent diagnosis with chlamydial, gonococcal or trichomonal infection 
- Have three of five criteria associated with increased risk of STIs

\section{Exclusion criteria}

- Currently pregnant or homeless

\section{Population}

Mean age 18.9 years.

420 women were randomized, 211 to home-based strategy and 209 to clinic-based strategy for CT and NG detection

Home-based specimen collection $(\mathrm{n}=211)$

Women in this group completed a questionnaire and received a home-testing kit for CT and NG at 6,12 and 18 months with instructions to take a vaginal swab and mail the sample to the laboratory.

Clinical-based specimen collection $(n=209)$

Women assigned to clinical group completed a questionnaire and received a postcard at 6, 12 and 18 months with an invitation to attend to clinic for a routine test for CT and NG each time

Outcomes - CT and NG tests completed (162/211)(117/209)

- CT and NG infections detected

Notes

Funding sources: "US Agency for Healthcare Research and Quality"

Role of funder: Not reported

Declarations of interest: None declared

Women did not receive any reminder or incentive for compliance. They reported rates of positive tests per 100 woman-years of follow-up. All participants provided informed consent. The study had ethical approval by participating institutions and clinics

Number of identifier register: ClinicalTrials.gov NCT00177437

\section{Risk of bias}

\begin{tabular}{l|l|l}
\hline Bias & Authors' judgement & Support for judgement \\
\hline $\begin{array}{l}\text { Random sequence generation (selection } \\
\text { bias) }\end{array}$ & Low risk & $\begin{array}{l}\text { Quote "Women were randomly assigned.. } \\
\text {-using a computer-generated blocked ran- } \\
\text { domisation sequence" }\end{array}$ \\
\hline Allocation concealment (selection bias) & Low risk & $\begin{array}{l}\text { Group allocation was concealed using } \\
\text { sealed envelopes. }\end{array}$ \\
\hline $\begin{array}{l}\text { Blinding of participants and personnel } \\
\text { (performance bias) } \\
\text { All outcomes }\end{array}$ & High risk & $\begin{array}{l}\text { No blinding; the outcomes are likely to be } \\
\text { influenced by lack of blinding }\end{array}$ \\
\hline
\end{tabular}

Blinding of outcome assessment (detection Unclear risk

The study did not address these outcomes. bias)

Subjective outcomes 
Cook 2007 (Continued)

\begin{tabular}{|c|c|c|}
\hline $\begin{array}{l}\text { Blinding of outcome assessment (detection } \\
\text { bias) } \\
\text { Objective outcomes }\end{array}$ & Low risk & $\begin{array}{l}\text { Clinicians and research assistants were } \\
\text { blinded to the participants' study assign- } \\
\text { ment }\end{array}$ \\
\hline
\end{tabular}

Incomplete outcome data (attrition bias) Unclear risk

Short-term outcomes

Incomplete outcome data (attrition bias) Unclear risk

Long-term outcomes

Selective reporting (reporting bias) Low risk

Other bias

Unclear risk
The number of tested completed at 6,12 and 18 month was not clearly reported, missing data were $58 \%$ and $56 \%$ for intervention and control group respectively

Only number of individuals not tested reported; however clearly information was not available to make a judgement

Protocol was available from trial registry. Primary outcome in protocol same as in trial

Both groups had clinical access to usual care if they were symptomatic

\section{Graseck 2010}

Methods

Participants
Setting: University-based clinic, two abortion clinics, community-based clinics in Missouri, United States

Study design: Parallel two arms. Enrollment ended August 1, 2009.

Sample size estimation a priori: Yes

\section{Inclusion criteria}

- Women aged 14 to 45 years

- Participant in Contraceptive CHOICE cohort study

- Using a long-acting reversible method of contraception

- Completed baseline clinical survey in the Contraceptive CHOICE cohort study

Exclusion criteria

- Patients with hysterectomy or tubal sterilization

- Living outside the United States at time of annual STI screening

Population

Mean age 26.1 years home group; and 25.5 years clinic group

548 women were randomized for home-based or clinic-based screening for CT and NG at 12 months after enrollment

Interventions

Home-based specimen collection $(\mathrm{n}=268)$

A collection kit was mailed to participants in home group: this contained a vaginal swab and instructions to take the sample and send it to the laboratory by prepaid mail. Baseline and 12 month follow-up interviews were performed.

Clinical-based specimen collection $(n=280)$

Women in clinical group were able to test with their regular health care provider or at local family planning clinics. Baseline and 12 month follow-up interviews were performed 


\section{Graseck 2010 (Continued)}

\begin{tabular}{ll}
\hline Outcomes & - CT and NG tests completed $(151 / 268)(92 / 280)$ \\
& - CT and NG infections detected $(3 / 151)(5 / 192)$
\end{tabular}

Notes

Funding sources: "Supported in part by an anonymous foundation, Midcareer Investigator Award in Women's Health Research (K24 HD01298), Clinical and Translational Science Awards (UL1RR024992), and Award Numbers TL1 RR024995, KL2RR024994, and K3054628 from the National Center for Research Resources (NCRR), a component of the National Institutes of Health (NIH) and NIH Roadmap for Medical Research"

Role of funder: Not reported

Declarations of interest: None declared

All participants with positive test and their sexual partners were treated. Ethical approval was obtained from Washington University School of Medicine Human Research Protection Office. All participants provided informed consent

Number of identifier register: ClinicalTrials.gov NCT01184157

Risk of bias

\begin{tabular}{|c|c|c|}
\hline Bias & Authors' judgement & Support for judgement \\
\hline $\begin{array}{l}\text { Random sequence generation (selection } \\
\text { bias) }\end{array}$ & Low risk & $\begin{array}{l}\text { Quote "Women were randomized using } \\
\text { computer-based randomization" }\end{array}$ \\
\hline Allocation concealment (selection bias) & Low risk & $\begin{array}{l}\text { Quote "Participants were blinded to ran- } \\
\text { domisation status until time of testing" }\end{array}$ \\
\hline $\begin{array}{l}\text { Blinding of participants and personnel } \\
\text { (performance bias) } \\
\text { All outcomes }\end{array}$ & High risk & $\begin{array}{l}\text { No blinding, the outcomes are likely to be } \\
\text { influenced by lack of blinding }\end{array}$ \\
\hline $\begin{array}{l}\text { Blinding of outcome assessment (detection } \\
\text { bias) } \\
\text { Subjective outcomes }\end{array}$ & High risk & $\begin{array}{l}\text { No blinding, assessment of subjective out- } \\
\text { comes might be influenced by lack of blind- } \\
\text { ing }\end{array}$ \\
\hline $\begin{array}{l}\text { Blinding of outcome assessment (detection } \\
\text { bias) } \\
\text { Objective outcomes }\end{array}$ & High risk & $\begin{array}{l}\text { Investigators were not blinded and lack } \\
\text { of blinding might influence the outcome } \\
\text { measurement }\end{array}$ \\
\hline $\begin{array}{l}\text { Incomplete outcome data (attrition bias) } \\
\text { Short-term outcomes }\end{array}$ & Low risk & $\begin{array}{l}\text { Participants allocated to home-based group } \\
\text { tested were } 151 / 268 \text {, control clinic-based } \\
\text { group } 163 / 280 \text { (medical records or speci- } \\
\text { men) }\end{array}$ \\
\hline $\begin{array}{l}\text { Incomplete outcome data (attrition bias) } \\
\text { Long-term outcomes }\end{array}$ & Unclear risk & $\begin{array}{l}\text { Only number of individuals not tested re- } \\
\text { ported; however clearly information was } \\
\text { not available to make a judgement }\end{array}$ \\
\hline
\end{tabular}

Home-based versus clinic-based specimen collection in the management of Chlamydia trachomatis and Neisseria gonorrhoeae 
Graseck 2010 (Continued)

\begin{tabular}{|c|c|c|}
\hline Selective reporting (reporting bias) & Low risk & $\begin{array}{l}\text { Protocol was available from trial registry. } \\
\text { Primary outcome in protocol same as in } \\
\text { trial }\end{array}$ \\
\hline Other bias & Low risk & No other bias identified. \\
\hline
\end{tabular}

Götz 2013

\begin{tabular}{l|l}
\hline Methods & $\begin{array}{l}\text { Setting: Urban STI clinic in the Netherlands } \\
\text { Study design: Parallel two arms. Enrolment between } 15 \text { March and } 15 \text { August } 2011 \\
\text { Sample size estimation a priori: Yes }\end{array}$ \\
\hline Participants & $\begin{array}{l}\text { Inclusion criteria } \\
\text { - Heterosexual men and women } \\
\text { - CT positive } \\
\text { Exclusion criteria } \\
\text { - Patients with PID, patients with clinically evident signs of infection treated at first } \\
\text { visit, patients notified by a sexual partner } \\
\text { - Pregnant women } \\
\text { - Patients with contra-indications for azithromycin } \\
\text { - Patients under } 16 \text { years } \\
\text { - MSM } \\
\text { Population } \\
\text { Mean age not reported. } \\
216 \text { participants with C. trachomatis infection were randomized, } 109 \text { to home-based } \\
\text { strategy and } 107 \text { to clinic-based strategy for CT retest }\end{array}$ \\
\hline
\end{tabular}

Interventions

Home-based specimen collection $(\mathrm{n}=109)$

Patients were entered in a database and completed a questionnaire. Participants were sent a test kit for retesting at 4 to 5 months after initial treatment. Test kit contained a sampling tube for urine collection for men or vaginal swab for women, to be sent back to the laboratory, free of charge. Reminders were sent 2 weeks after no response.

Clinical-based specimen collection $(n=107)$

Patients were entered in a database and completed a questionnaire. Participants were asked to visit the clinic for retesting at 4 to 5 months after initial treatment and received a test kit with sampling tube for urine collection for men or vaginal swab for women. Reminders were sent 7 days if no response

Outcomes

- CT retest completed $(50 / 109)(25 / 107)$

- CT repeat infections detected $(8 / 50)(5 / 25)$

Notes

Funding sources: "ZonMW, Ministry of Health The Netherlands, grant number 12400001 and by RIVM, the Netherlands"

Declarations of interest: None declared.

Role of funder: Not reported.

Not reported if partners' tests CT positive were treated or if all participants with positive test were treated. Ethical approval was obtained. Participants provided informed consent Number of identifier register: Not found. 
Götz 2013 (Continued)

\section{Risk of bias}

\begin{tabular}{|c|c|c|}
\hline Bias & Authors' judgement & Support for judgement \\
\hline $\begin{array}{l}\text { Random sequence generation (selection } \\
\text { bias) }\end{array}$ & Low risk & $\begin{array}{l}\text { Quote "Computerized randomisation into. } \\
\text {.. was done using and anonymous list of ID } \\
\text { numbers and sex of participants" }\end{array}$ \\
\hline Allocation concealment (selection bias) & Unclear risk & $\begin{array}{l}\text { No details on allocation concealment given } \\
\text { in the report. }\end{array}$ \\
\hline $\begin{array}{l}\text { Blinding of participants and personnel } \\
\text { (performance bias) } \\
\text { All outcomes }\end{array}$ & High risk & $\begin{array}{l}\text { No blinding, the outcomes are likely to be } \\
\text { influenced by lack of blinding }\end{array}$ \\
\hline $\begin{array}{l}\text { Blinding of outcome assessment (detection } \\
\text { bias) } \\
\text { Subjective outcomes }\end{array}$ & Unclear risk & No subjective outcomes reported. \\
\hline $\begin{array}{l}\text { Blinding of outcome assessment (detection } \\
\text { bias) } \\
\text { Objective outcomes }\end{array}$ & High risk & $\begin{array}{l}\text { Investigators were not blinded and lack } \\
\text { of blinding might influence the outcome } \\
\text { measurement }\end{array}$ \\
\hline $\begin{array}{l}\text { Incomplete outcome data (attrition bias) } \\
\text { Short-term outcomes }\end{array}$ & High risk & $\begin{array}{l}\text { Home-based group participants tested were } \\
50 / 109 \text {, clinic-based group } 25 / 107 . \text { More } \\
\text { than } 20 \% \text { participants were not tested and } \\
\text { the missing data were not balanced in the } \\
\text { groups }\end{array}$ \\
\hline $\begin{array}{l}\text { Incomplete outcome data (attrition bias) } \\
\text { Long-term outcomes }\end{array}$ & Unclear risk & $\begin{array}{l}\text { Only number of individuals not tested re- } \\
\text { ported ; however clearly information was } \\
\text { not available to make a judgement, }\end{array}$ \\
\hline Selective reporting (reporting bias) & Unclear risk & $\begin{array}{l}\text { Protocol was not available from } 3 \text { trial reg- } \\
\text { istries. No information available in meth- } \\
\text { ods section to make a judgement, }\end{array}$ \\
\hline Other bias & High risk & $\begin{array}{l}\text { Reminders added to management strategy, } \\
\text { also this study evaluated re-testing, }\end{array}$ \\
\hline
\end{tabular}




Inclusion criteria
Participants Women, aged 14 to 25 years
- At least grade 5 education
Exclusion criteria
- Genital ulcers or gynaecological symptoms in need of immediate care
Population
Mean age 20 years.
626 women were randomized to home-based vs. clinic-based screening for NG, CT and
Trichomonas vaginalis (TV)

Participants in home group received a home kit with instructions to take two vaginal swabs, two questionnaires and educational material, and envelope with pre-paid postage to return the samples. They had a clinic appointment 6 weeks after enrollment and reminders were sent on three occasions to contact women who missed this visit.

Clinical-based specimen collection $(\mathrm{n}=313)$

Participants in the clinic group received an identical kit with educational material and a clinic appointment card; at the clinic women received two swabs for self-sampling. They had a clinic appointment 6 weeks after enrollment and reminders were sent on three occasions to contact women who missed this visit

Outcomes
- Test completed (Home 143/313) (Clinic 131/313)

- Feasibility and acceptability of testing

Funding sources: The trial was funded by the Office of Population and Reproduc-
tive Health, Bureau for Global Health, US Agency for International Development and
Parthenon Trust and the William and Flora Hewlett Foundation
Role of funder: Not reported
Declarations of interest: None declared
It is unclear if all participants with positive test and their sexual partners were treated.
Ethical approval was obtained from ethical committees at the University of Cape Town
and the Population Council. All participants provided informed consent
Number of identifier register: Not found

\section{Risk of bias}

\begin{tabular}{|c|c|c|}
\hline Bias & Authors' judgement & Support for judgement \\
\hline $\begin{array}{l}\text { Random sequence generation (selection } \\
\text { bias) }\end{array}$ & Unclear risk & $\begin{array}{l}\text { Quote "Women were randomised... using a } \\
\text { random sequence", not reported any detail } \\
\text { about the process of sequence generation }\end{array}$ \\
\hline Allocation concealment (selection bias) & Low risk & $\begin{array}{l}\text { Group allocation was conceal using sealed } \\
\text { envelopes. }\end{array}$ \\
\hline
\end{tabular}


Blinding of participants and personnel High risk (performance bias)

All outcomes

Blinding of outcome assessment (detection High risk bias)

Subjective outcomes

Blinding of outcome assessment (detection High risk bias)

Objective outcomes

Incomplete outcome data (attrition bias) Unclear risk Short-term outcomes

Incomplete outcome data (attrition bias) Unclear risk

Long-term outcomes

Selective reporting (reporting bias) Unclear risk

Other bias

High risk
No blinding, the outcomes are likely to be influenced by lack of blinding

No blinding, assessment of subjective outcomes might be influenced by lack of blinding

Investigators were not blinded and lack of blinding might influence the outcome measurement

In home-based group 143/313 participants were tested and in clinic-based group 131/ 313 were tested, the missing data were balanced

Only number of individuals not tested reported; however clearly information was not available to make a judgement

Protocol was not available from 3 trial registries. No information available in methods section to make a judgement

Reminders added to management strategy.

\section{Lippman 2007}

Methods

\begin{tabular}{ll} 
& $\begin{array}{l}\text { Study design: Parallel two arms. Enrollment between April and November } 2004 \\
\text { Sample size estimation a priori: No }\end{array}$ \\
\hline Participants & $\begin{array}{l}\text { Inclusion criteria } \\
\text { - Women, aged } 18 \text { to } 40 \text { years } \\
\text { - Ability to read and to follow collection and testing instructions } \\
\text { Exclusion criteria } \\
\text { - Not specified } \\
\text { Population } \\
\text { Mean age } 27.6 \text { years } \\
818 \text { women were randomized, } 410 \text { to home-based strategy and } 408 \text { to clinic-based } \\
\text { strategy for CT, TV and NG detection }\end{array}$ \\
\hline
\end{tabular}

Interventions
Setting: Low-income clinic population in São Paulo, Brazil

Study design: Parallel two arms. Enrollment between April and November 2004

nclusion criteria

- Women, aged 18 to 40 years

- Ability to read and to follow collection and testing instructions

- Not specified

Population strategy for CT, TV and NG detection

Home-based specimen collection $(n=410)$

Participants in home group received a kit to take the CT, NG and TV test at home, then in the following 7 days they had to return the sample to study clinic. They also had a questionnaire on acceptability.

Clinical-based specimen collection $(n=408)$ 
Participants in clinic group received an identical kit with STI information and an appointment card for testing at the study clinic. Additionally during the appointment a pelvic examination was performed and two endocervical samples collected. Afterwards they answered a questionnaire on acceptability

Outcomes

Notes
- Test completed (393/410)(394/408)

- Feasibility and acceptability of testing

Funding sources: "this study was funded by the Office of Population and Reproductive Health, Bureau for Global Health, U.S. Agency for International Development"

Declarations of interest: Not reported

Role of funder: Not reported

Ethical approval was obtained from ethical committees of the Irmandade Santa Casa de Misericórdia de São Paulo, the Brazilian National Ethics Committee and the Population Council. All participants provided informed consent

Number of identifier register: Not found

\section{Risk of bias}

\begin{tabular}{lll} 
Bias & Authors' judgement & Support for judgement \\
\hline $\begin{array}{l}\text { Random sequence generation (selection } \\
\text { bias) }\end{array}$ & Low risk & $\begin{array}{l}\text { Quote “identification numbers were ran- } \\
\text { domized before study commencement in } \\
\text { blocks of 16” }\end{array}$ \\
\hline Allocation concealment (selection bias) & Low risk & $\begin{array}{l}\text { Group allocation was concealed using } \\
\text { sealed envelopes }\end{array}$
\end{tabular}

Blinding of participants and personnel High risk (performance bias)

No blinding, the outcomes are likely to be All outcomes influenced by lack of blinding

Blinding of outcome assessment (detection Unclear risk bias)

Subjective outcomes

Blinding of outcome assessment (detection Unclear risk bias)

Objective outcomes

Incomplete outcome data (attrition bias) Low risk

Short-term outcomes

Incomplete outcome data (attrition bias) Unclear risk Long-term outcomes
There is not sufficient information to permit judgement

It is not reported if the laboratory personnel or assessors were blinded

Participants tested in home-based group were 393/410 and 394/408 in clinic-based group

Only one long-term outcome was evaluated, number of individuals not tested; however clearly information was not available to make a judgement 
Lippman 2007 (Continued)

\begin{tabular}{l|l|l}
\hline Selective reporting (reporting bias) & Unclear risk & $\begin{array}{l}\text { Protocol was not available from } 3 \text { trial reg- } \\
\text { istries. No information available in meth- } \\
\text { ods section to make a judgement }\end{array}$ \\
\hline Other bias & High risk & Reminders added to management strategy \\
\hline
\end{tabular}

\section{Ostergaard 1998}

\begin{tabular}{|c|c|}
\hline Methods & $\begin{array}{l}\text { Setting: High schools in Aarhus, Denmark } \\
\text { Study design: Cluster randomized trial, parallel two arms. Enrollment between January } \\
1997 \text { and April } 1997 \\
\text { Sample size estimation a priori: No }\end{array}$ \\
\hline Participants & $\begin{array}{l}\text { Inclusion criteria } \\
\text { - Male and female students who returned the questionnaire and were sexually } \\
\text { experienced } \\
\text { Exclusion criteria } \\
\text { - Not specified } \\
\text { Population } \\
\text { Mean age females } 18 \text { years, males } 18.2 \text { years. } \\
8909 \text { students were randomized, } 4336 \text { to home-based strategy ( } 2603 \text { women and } 1733 \\
\text { men) and } 4573 \text { to clinic-based strategy ( } 2884 \text { women and } 1689 \text { men) for CT detection. } \\
\text { To deal with unit analysis issues about cluster-randomized studies we used an ICC } 0 \text {, } \\
00119 \text {, average cluster size of } 524 \text {; hence the effective sample size for home group was } \\
2673 \text { and } 2819 \text { for clinic group }\end{array}$ \\
\hline
\end{tabular}

Interventions

Home-based specimen collection $(\mathrm{n}=2673)$

In the home group the students completed a questionnaire and received information regarding CT infection; female students were asked to collect two urine samples and one vaginal flush sample, males were asked to collect one first void urine sample and mail from home to the laboratory.

Clinical-based specimen collection $(\mathrm{n}=2819)$

In the clinic group the students completed a questionnaire and received information regarding CT infection; they were offered a free test from their doctor or at the local clinic

Outcomes

- Number of students tested (799/2673)(41/2819)

- Number of students infected (33/799)(4/41)

Notes

Funding sources: "The study was funded by the Danish National Board of Health, Løvens Kemiske Fabriks Research Foundation, Nycomed DAK, Pfizer, and Chairman Jacob Madsen and Hustru Olga Madsen's foundation"

Role of funder: Not reported

Declarations of interest: None declared

It is unclear if all participants with positive test and their sexual partners were treated. Ethical approval was obtained from ethics committee and the Danish Data Protection Agency. Unclear whether consent was obtained

Number of identifier register: Not found 


\section{Ostergaard 1998 (Continued)}

\section{Risk of bias}

\begin{tabular}{|c|c|c|}
\hline Bias & Authors' judgement & Support for judgement \\
\hline $\begin{array}{l}\text { Random sequence generation (selection } \\
\text { bias) }\end{array}$ & Unclear risk & $\begin{array}{l}\text { Quote "We randomised all } 17 \text { high } \\
\text { schools": details about the process of se- } \\
\text { quence generation for cluster-randomiza- } \\
\text { tion not reported }\end{array}$ \\
\hline Allocation concealment (selection bias) & Unclear risk & $\begin{array}{l}\text { No details on allocation concealment given } \\
\text { in the report. }\end{array}$ \\
\hline $\begin{array}{l}\text { Blinding of participants and personnel } \\
\text { (performance bias) } \\
\text { All outcomes }\end{array}$ & High risk & $\begin{array}{l}\text { No blinding, the outcomes are likely to be } \\
\text { influenced by lack of blinding }\end{array}$ \\
\hline $\begin{array}{l}\text { Blinding of outcome assessment (detection } \\
\text { bias) } \\
\text { Subjective outcomes }\end{array}$ & Unclear risk & No subjective outcomes reported. \\
\hline $\begin{array}{l}\text { Blinding of outcome assessment (detection } \\
\text { bias) } \\
\text { Objective outcomes }\end{array}$ & Unclear risk & $\begin{array}{l}\text { It is not reported if the laboratory personnel } \\
\text { or assessors were blinded }\end{array}$ \\
\hline $\begin{array}{l}\text { Incomplete outcome data (attrition bias) } \\
\text { Short-term outcomes }\end{array}$ & High risk & $\begin{array}{l}\text { After we used the effective sample size } \\
\text { for this cluster-randomized study, the at- } \\
\text { trition rate was } 799 / 2673 \text { for home-based } \\
\text { group; and for clinic-based group it was } 41 / \\
2819 \text {. More than } 20 \% \text { participants were } \\
\text { not tested and the missing data were not } \\
\text { balanced in the groups }\end{array}$ \\
\hline $\begin{array}{l}\text { Incomplete outcome data (attrition bias) } \\
\text { Long-term outcomes }\end{array}$ & Unclear risk & $\begin{array}{l}\text { Only number of individuals not tested re- } \\
\text { ported; however clearly information was } \\
\text { not available to make a judgement }\end{array}$ \\
\hline Selective reporting (reporting bias) & Unclear risk & $\begin{array}{l}\text { Protocol was not available from } 3 \text { trial reg- } \\
\text { istries. No information available in meth- } \\
\text { ods section to make a judgement }\end{array}$ \\
\hline Other bias & Unclear risk & No other bias identified. \\
\hline
\end{tabular}




\begin{tabular}{|c|c|}
\hline Methods & $\begin{array}{l}\text { Setting: General practices in four counties in Denmark } \\
\text { Study design: Parallel two arms. Enrollment between February } 1999 \text { and March } 2000 \\
\text { Sample size estimation a priori: No }\end{array}$ \\
\hline Participants & $\begin{array}{l}\text { Inclusion criteria } \\
\text { - Patients with CT positive swab in the routine laboratory } \\
\text { - Completed questionnaire } \\
\text { Exclusion criteria } \\
\text { - Not specified } \\
\text { Population } \\
\text { Mean age index women } 23 \text { years, index men } 25 \text { years. } \\
1826 \text { patients with C. trachomatis-positive swab test were randomized, } 734 \text { sexual part- } \\
\text { ners were contacted and they received the intervention: } 398 \text { received the home-based } \\
\text { strategy ( } 342 \text { women and } 56 \text { men); and } 336 \text { received the clinic-based strategy ( } 289 \\
\text { women and } 47 \text { men) for CT detection }\end{array}$ \\
\hline
\end{tabular}

Index patients gave or mailed the collection kit to their partners; in the home group the partners mailed the samples to the laboratory in post-paid envelopes.

Clinical-based specimen collection for sexual partners $(n=336)$

In the office group partners needed to go to heath care provider to obtain a sample, using the provided specimen collection kit

Outcomes
- Number of sexual partners tested (233/398)(97/336)

- Number of sexual partners infected $(91 / 233)(50 / 97)$

\section{Notes \\ Funding sources: "The study was supported by grants from the Danish National Board of Health, Danish Medical Research Council, Danish Centre for Evaluation and Health Technology Assessment (DACEHTA), Aage Bang's Fund, Helga og Peter Kornings Fond, and Pfizer Denmark A/S" \\ Role of funder: Not reported \\ Declarations of interest: None declared \\ It is unclear if all participants with positive test and their sexual partners were treated. Ethical approval was obtained from the Danish ethics committee system. Implied consent Number of identifier register: Not found}

\section{Risk of bias}

\begin{tabular}{lll} 
Bias & Authors' judgement & Support for judgement \\
\hline $\begin{array}{l}\text { Random sequence generation (selection } \\
\text { bias) }\end{array}$ & Unclear risk & $\begin{array}{l}\text { Quote "We randomised the index pa- } \\
\text { tients", details about the process of se- } \\
\text { quence generation not reported }\end{array}$ \\
\hline $\begin{array}{l}\text { Allocation concealment (selection bias) } \\
\text { Low risk }\end{array}$ & Lllocation was done by central randomiza- \\
tion
\end{tabular}




\section{Ostergaard 2003 (Continued)}

Blinding of participants and personnel High risk (performance bias)

All outcomes

Blinding of outcome assessment (detection Unclear risk bias)

Subjective outcomes

Blinding of outcome assessment (detection Unclear risk bias)

Objective outcomes

Incomplete outcome data (attrition bias) High risk

Short-term outcomes

Incomplete outcome data (attrition bias) Unclear risk

Long-term outcomes

Selective reporting (reporting bias) Unclear risk

Other bias

High risk
No blinding, the outcomes are likely to be influenced by lack of blinding

No subjective outcomes reported

It is not reported if the laboratory personnel or assessors were blinded

In home-based group 233/398 participants were tested and in clinic-based group 97/ 336 were tested. More than $20 \%$ participants were not tested and the missing data were not balanced in the groups

Only number of individuals not tested reported; however clearly information was not available to make a judgement

Protocol was not available from 3 trial registries. No information available in methods section to make a judgement

Participants were sexual partners of CT positive patients

Reagan 2012

Methods

Setting: Low-income area health clinics and local colleges, word of mouth self referral, and a WU school of Medicine outreach group in St. Louis Missouri, United States Study design: Parallel two arms. Enrollment between June 2011 and September 2011 Sample size estimation a priori: Yes

Participants

\section{Inclusion criteria}

- Men aged 18 to 45 years

- Residing in St. Louis City or County

- English-speaking

Exclusion criteria

- Not specified

Population

Mean age 31.2 home group. 30.3 clinic group.

200 men were randomized, 100 to home-based strategy and 100 to clinic-based strategy for CT and NG detection 


\begin{tabular}{ll}
\hline Interventions & $\begin{array}{l}\text { Home-based specimen collection }(\mathrm{n}=100) \\
\text { Participants received a screening kit at their address to collect a urine sample at home. } \\
\text { Then they returned the urine sample to laboratory through prepaid mailer. They com- } \\
\text { pleted a baseline and follow-up questionnaire } \\
\text { Clinical-based specimen collection }(\mathrm{n}=100) \\
\text { Participants in clinic group received a screening kit on arrival at the research clinic, they } \\
\text { collected the urine sample and returned it to the staff. They completed a baseline and } \\
\text { follow-up questionnaire }\end{array}$ \\
\hline Outcomes & $\begin{array}{l}\text { - Number of men who complete testing }(72 / 100)(48 / 100) \\
\text { Notes }\end{array}$ \\
\hline $\begin{array}{l}\text { Funding sources: Anonymous Foundation, National Institutes of Health (NIH) and } \\
\text { grant from the Doris Duke Charitable Foundation } \\
\text { Role of funder: Not reported } \\
\text { Declarations of interest: None } \\
\text { It is unclear if all participants with positive test and their sexual partners were treated. } \\
\text { Ethical approval was obtained from ethical committees of Washington University in St. } \\
\text { Louis Human Research Protection Office. All participants provided informed consent } \\
\text { Number of identifier register: ClinicalTrials.gov NCT01654991 }\end{array}$ \\
\hline
\end{tabular}

\section{Risk of bias}

\begin{tabular}{|c|c|c|}
\hline Bias & Authors' judgement & Support for judgement \\
\hline $\begin{array}{l}\text { Random sequence generation (selection } \\
\text { bias) }\end{array}$ & Low risk & $\begin{array}{l}\text { Quote "Using a computer-generated } 1: 1 \\
\text { randomization scheme... by random gen- } \\
\text { erator function" }\end{array}$ \\
\hline Allocation concealment (selection bias) & Unclear risk & $\begin{array}{l}\text { No details on allocation concealment given } \\
\text { in the report }\end{array}$ \\
\hline
\end{tabular}

Blinding of participants and personnel High risk (performance bias)

All outcomes
No blinding, the outcomes are likely to be influenced by lack of blinding

No subjective outcomes reported

Blinding of outcome assessment (detection Unclear risk bias)

Subjective outcomes

Blinding of outcome assessment (detection High risk bias)

Objective outcomes

Incomplete outcome data (attrition bias) High risk Short-term outcomes
Investigators were not blinded and lack of blinding might influence the outcome measurement
In home-based group 72/100 participants were tested and in clinic-based group 48/ 100 were tested. More than $20 \%$ participants were not tested and the missing data 
were not balanced in the group

\begin{tabular}{|c|c|c|}
\hline $\begin{array}{l}\text { Incomplete outcome data (attrition bias) } \\
\text { Long-term outcomes }\end{array}$ & Unclear risk & $\begin{array}{l}\text { Only number of individuals not tested re- } \\
\text { ported; however clearly information was } \\
\text { not available to make a judgement }\end{array}$ \\
\hline Selective reporting (reporting bias) & Low risk & $\begin{array}{l}\text { Protocol was available from trial registry. } \\
\text { Primary outcome in protocol same as in } \\
\text { trial }\end{array}$ \\
\hline Other bias & High risk & $\begin{array}{l}\text { Use of an economic incentive for partici- } \\
\text { pants }\end{array}$ \\
\hline
\end{tabular}

Xu 2011

Methods

Setting: STI clinics and family planning clinics in New Orleans, Louisiana, St Louis, Missouri, and Jackson, Mississippi, United States

Study design: Parallel two arms. Enrollment between 2005 and 2007

Sample size estimation a priori: Yes

Participants

Inclusion criteria

- Women 16 years and older

- CT positive

Exclusion criteria

- Pregnant or women trying to conceive

- Women who are planning to move in the following 3 months

- Currently living outside the study areas

- Inability to understand spoken English adequately

- Self-reported HIV infection, other serious illnesses or disability

- Self-reported allergy to macrolide antibiotics such as azithromycin

- Referrals from providers or clinics other than the STD or family planning clinics, unless women are re-tested at the STD clinics and test positive for chlamydia

\section{Population}

Mean age 22 years.

1292 women with $C$. trachomatis infection were randomized to rescreening, 639 to home-based strategy and 653 to clinic-based strategy

Interventions

Home-based specimen collection $(n=639)$

Participants in home group were mailed a vaginal swab kit for self collection at home and they returned the sample via mail

Clinical-based specimen collection $(n=653)$

Participants in clinic group were given an appointment to return to clinics for rescreening for CT infection

Outcomes

- Rescreening 3 months after treatment (189/639)(120/653)

- Reinfection (29/189)(27/120) 
Xu 2011 (Continued)

\begin{tabular}{ll}
\hline Notes & $\begin{array}{l}\text { Funding sources: "Funded by Centers for Disease Control and Prevention" } \\
\text { Role of funder: Not reported } \\
\text { Declarations of interest: None declared }\end{array}$ \\
It is unclear if all participants with positive test and their sexual partners were treated. \\
Ethical approval was obtained from ethical committees of Louisiana State University \\
Health Sciences Center, Washington University, University of Mississippi State Depart- \\
ment of Health, and the CDC. All participants provided informed consent \\
Number of identifier register: ClinicalTrials.gov NCT00132457
\end{tabular}

Risk of bias

\begin{tabular}{l|l|l}
\hline Bias & Authors' judgement & Support for judgement \\
\hline $\begin{array}{l}\text { Random sequence generation (selection } \\
\text { bias) }\end{array}$ & Low risk & $\begin{array}{l}\text { Quote "Women were randomly assigned... } \\
\text { according to a random number generator.. } \\
\text {. with a block size of 12" }\end{array}$ \\
\hline Allocation concealment (selection bias) & Low risk & $\begin{array}{l}\text { Group allocation was concealed using } \\
\text { sealed envelopes }\end{array}$ \\
\hline
\end{tabular}

Blinding of participants and personnel High risk

No blinding, the outcomes are likely to be (performance bias) influenced by lack of blinding

All outcomes

Blinding of outcome assessment (detection Unclear risk bias)

Subjective outcomes

Blinding of outcome assessment (detection Unclear risk bias)

Objective outcomes

It is not reported if the laboratory personnel or assessors were blinded

Incomplete outcome data (attrition bias) High risk

Short-term outcomes

No subjective outcomes reported

(20)

In home-based group 189/639 participants were tested and in clinic-based group 120/ 653 were tested. More than $20 \%$ participants were not tested and the missing data were not balanced in the group

Incomplete outcome data (attrition bias) Unclear risk

Only number of individuals not tested reLong-term outcomes ported; however clearly information was not available to make a judgement

Selective reporting (reporting bias) Low risk

Protocol was available from trial registry. Primary outcome in protocol same as in trial

Other bias

High risk

Reminders added to management strategy, also this study evaluated re-testing 
$\mathrm{CT}=$ Chlamydia trachomatis

$\mathrm{NG}=$ Neisseria gonorrhoeae

Characteristics of excluded studies [ordered by study ID]

\begin{tabular}{|c|c|}
\hline Study & Reason for exclusion \\
\hline Andersen 2002 & No comparison, usual care, only symptomatic participants were evaluated \\
\hline Andersen 2011 & $\begin{array}{l}\text { No comparison, usual care, only symptomatic participants were evaluated. Follow-up } 9 \text { years after Andersen } \\
2002\end{array}$ \\
\hline Buhrer-Skinner 2011 & Not an RCT \\
\hline Emmerton 2011 & Not an RCT \\
\hline Falk 2014 & Not an RCT \\
\hline Gray 1998 & Not an RCT \\
\hline Klovstad 2013 & No comparison, usual care, only symptomatic participants were evaluated \\
\hline Ostergaard 1999 & Duplicate in Dutch language from Ostergaard 1998 \\
\hline Ostergaard 2000 & Reports on 1 year follow-up for Ostergaard 1998 , new data were added to the included study \\
\hline Scholes 2007 & No comparison, usual care, only symptomatic participants were evaluated \\
\hline Sparks 2004 & Not an RCT \\
\hline Van Valkengoed 2002 & Not an RCT \\
\hline
\end{tabular}

RCT: randomized controlled trial

Characteristics of studies awaiting assessment [ordered by study ID]

Apoola 2009

Methods Setting: Genito-Urinary clinic in Derbyshire, UK

Study design: RCT, parallel two arms. Enrollment between February 282006 and March 312007

Funding sources: None

Declarations of interest: None declared

Home-based versus clinic-based specimen collection in the management of Chlamydia trachomatis and Neisseria gonorrhoeae 
Apoola 2009 (Continued)

\begin{tabular}{|c|c|}
\hline Participants & $\begin{array}{l}\text { Inclusion criteria } \\
\text { - Women } \\
\text { - CT positive } \\
\text { Exclusion criteria } \\
\text { - Patients whose sexual contacts are not in Derbyshire or are untraceable } \\
\text { - Sexual contacts under the age of } 16 \\
\text { Population } \\
200 \text { women with } C \text {. trachomatis infection were randomized to partner notification, } 100 \text { to swab testing arm and } 100 \\
\text { to urine testing arm }\end{array}$ \\
\hline Interventions & $\begin{array}{l}\text { Swab testing arm }(\mathrm{n}=100) \\
\text { Conventional partner notification using urethral swab test at clinic } \\
\text { Urine testing arm }(\mathrm{n}=100) \\
\text { Index patient gave to male sexual partners contact slip and urine sampling kit to collect the sample at home and then } \\
\text { return to clinic for diagnosis and management }\end{array}$ \\
\hline Outcomes & Number of partners treated per index case \\
\hline Notes & $\begin{array}{l}\text { We wrote to contact author for further information about outcome data of exact number of sexual partners, but we } \\
\text { did not obtain any information }\end{array}$ \\
\hline
\end{tabular}

\section{Characteristics of ongoing studies [ordered by study ID]}

\section{De Barbeyrac 2013}

\begin{tabular}{ll}
\hline Trial name or title & Chlamy-web \\
\hline Methods & RCT \\
\hline Participants & Young people 18 to 24 years old recruitment on Internet information web site \\
\hline Interventions & Free home-based self-sampling test vs traditional information system at screening center \\
\hline Outcomes & Self-sampling was proposed to 5531 people, 1616 were tested, global prevalence 6.8\% \\
\hline Starting date & Not reported \\
\hline Contact information & Bertille.de-Barbeyrac@u-bordeaux.fr \\
\hline Notes & $\begin{array}{l}\text { This study is still ongoing, there are no data on traditional screening. The authors did not provide more } \\
\text { information }\end{array}$ \\
\hline
\end{tabular}


Trial name or title

REACT: a randomized controlled trial assessing the effectiveness of home-collection to increase chlamydia retesting and detect repeat positive tests

\begin{tabular}{ll}
\hline Methods & Non-blinded, randomized controlled trial \\
\hline Participants & Heterosexual men, MSM or women who have a diagnosis of chlamydia infection \\
\hline Interventions & SMS reminder and home-based, self-collected samples or an SMS reminder and clinic testing \\
\hline Outcomes & $\begin{array}{l}\text { Proportion of patients who retest between } 1 \text { to } 4 \text { months after a chlamydia diagnosis, repeat positive test rate, } \\
\text { reinfection rate, acceptability of home testing with SMS reminders and cost effectiveness of home testing }\end{array}$ \\
\hline Starting date & Not reported \\
\hline Contact information & ksmith@kirby.unsw.edu.au \\
\hline Notes & Trial registration: Australian and New Zealand Clinical Trials Registry ACTRN12611000968976 \\
\hline
\end{tabular}


DATA AND ANALYSES

Comparison 1. Home-based vs clinic-based specimen collection for CT and NG

\begin{tabular}{|c|c|c|c|c|}
\hline Outcome or subgroup title & $\begin{array}{l}\text { No. of } \\
\text { studies }\end{array}$ & $\begin{array}{c}\text { No. of } \\
\text { participants }\end{array}$ & Statistical method & Effect size \\
\hline 1 Index Case Management & 3 & 1566 & Risk Ratio (M-H, Fixed, 95\% CI) & $0.88[0.60,1.29]$ \\
\hline 2 Proportion of individuals tested & 10 & & Risk Ratio (M-H, Random, 95\% CI) & Totals not selected \\
\hline $\begin{array}{l}3 \text { Proportion of individual tested } \\
\text { grouped by sex }\end{array}$ & 9 & & Odds Ratio (M-H, Random, 95\% CI) & Totals not selected \\
\hline 3.1 Female & 7 & & Odds Ratio (M-H, Random, 95\% CI) & $0.0[0.0,0.0]$ \\
\hline 3.2 Male & 4 & & Odds Ratio (M-H, Random, 95\% CI) & $0.0[0.0,0.0]$ \\
\hline $\begin{array}{l}4 \text { Proportion of individual tested } \\
\text { grouped by risk }\end{array}$ & 10 & & Risk Ratio (M-H, Random, 95\% CI) & Totals not selected \\
\hline 4.1 High Risk & 5 & & Risk Ratio (M-H, Random, 95\% CI) & $0.0[0.0,0.0]$ \\
\hline 4.2 Low Risk & 5 & & Risk Ratio (M-H, Random, 95\% CI) & $0.0[0.0,0.0]$ \\
\hline $\begin{array}{l}5 \text { Proportion of individual } \\
\text { tested grouped by method of } \\
\text { returning specimens }\end{array}$ & 10 & & Risk Ratio (M-H, Random, 95\% CI) & Totals not selected \\
\hline 5.1 Mail & 9 & & Risk Ratio (M-H, Random, 95\% CI) & $0.0[0.0,0.0]$ \\
\hline 5.2 Personally & 1 & & Risk Ratio (M-H, Random, 95\% CI) & $0.0[0.0,0.0]$ \\
\hline $\begin{array}{l}6 \text { Proportion of individual tested } \\
\text { grouped by use of reminders }\end{array}$ & 7 & & Risk Difference (M-H, Random, 95\% CI) & Totals not selected \\
\hline 6.1 No reminders & 2 & & Risk Difference (M-H, Random, 95\% CI) & $0.0[0.0,0.0]$ \\
\hline 6.2 Reminders & 5 & & Risk Difference (M-H, Random, 95\% CI) & $0.0[0.0,0.0]$ \\
\hline 7 Positive test prevalence & 9 & 3041 & Risk Ratio (M-H, Fixed, 95\% CI) & $0.72[0.61,0.86]$ \\
\hline
\end{tabular}


Analysis I.I. Comparison I Home-based vs clinic-based specimen collection for CT and NG, Outcome I Index Case Management.

\begin{tabular}{|c|c|c|c|c|c|}
\hline \multicolumn{6}{|c|}{ Comparison: I Home-based vs clinic-based specimen collection for CT and NG } \\
\hline \multicolumn{6}{|c|}{ Outcome: I Index Case Management } \\
\hline \multirow[t]{2}{*}{ Study or subgroup } & Home & Clinic & Risk Ratio & Weight & Risk Ratio \\
\hline & $\mathrm{n} / \mathrm{N}$ & $\mathrm{n} / \mathrm{N}$ & M-H,Fixed,95\% Cl & & M-H,Fixed, $95 \% \mathrm{Cl}$ \\
\hline Graseck 2010 & $3 / 268$ & $5 / 280$ & $\rightarrow$ & $9.6 \%$ & $0.63[0.15,2.60]$ \\
\hline Lippman 2007 & $38 / 410$ & $43 / 408$ & $\mathbf{B}$ & $84.5 \%$ & $0.88[0.58,1.33]$ \\
\hline Reagan 2012 & $4 / 100$ & $3 / 100$ & $\rightarrow$ & $5.9 \%$ & $1.33[0.31,5.81]$ \\
\hline Total $(95 \% \mathrm{CI})$ & 778 & 788 & 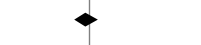 & $100.0 \%$ & $0.88[0.60,1.29]$ \\
\hline \multicolumn{6}{|c|}{ Total events: 45 (Home), 5 I (Clinic) } \\
\hline \multicolumn{6}{|c|}{ Heterogeneity: $\mathrm{Ch}^{2}{ }^{2}=0.52, \mathrm{df}=2(\mathrm{P}=0.77) ; \mathrm{I}^{2}=0.0 \%$} \\
\hline \multicolumn{6}{|c|}{ Test for overall effect: $Z=0.64(P=0.52)$} \\
\hline \multicolumn{6}{|c|}{ Test for subgroup differences: Not applicable } \\
\hline
\end{tabular}


Analysis I.2. Comparison I Home-based vs clinic-based specimen collection for CT and NG, Outcome 2 Proportion of individuals tested.

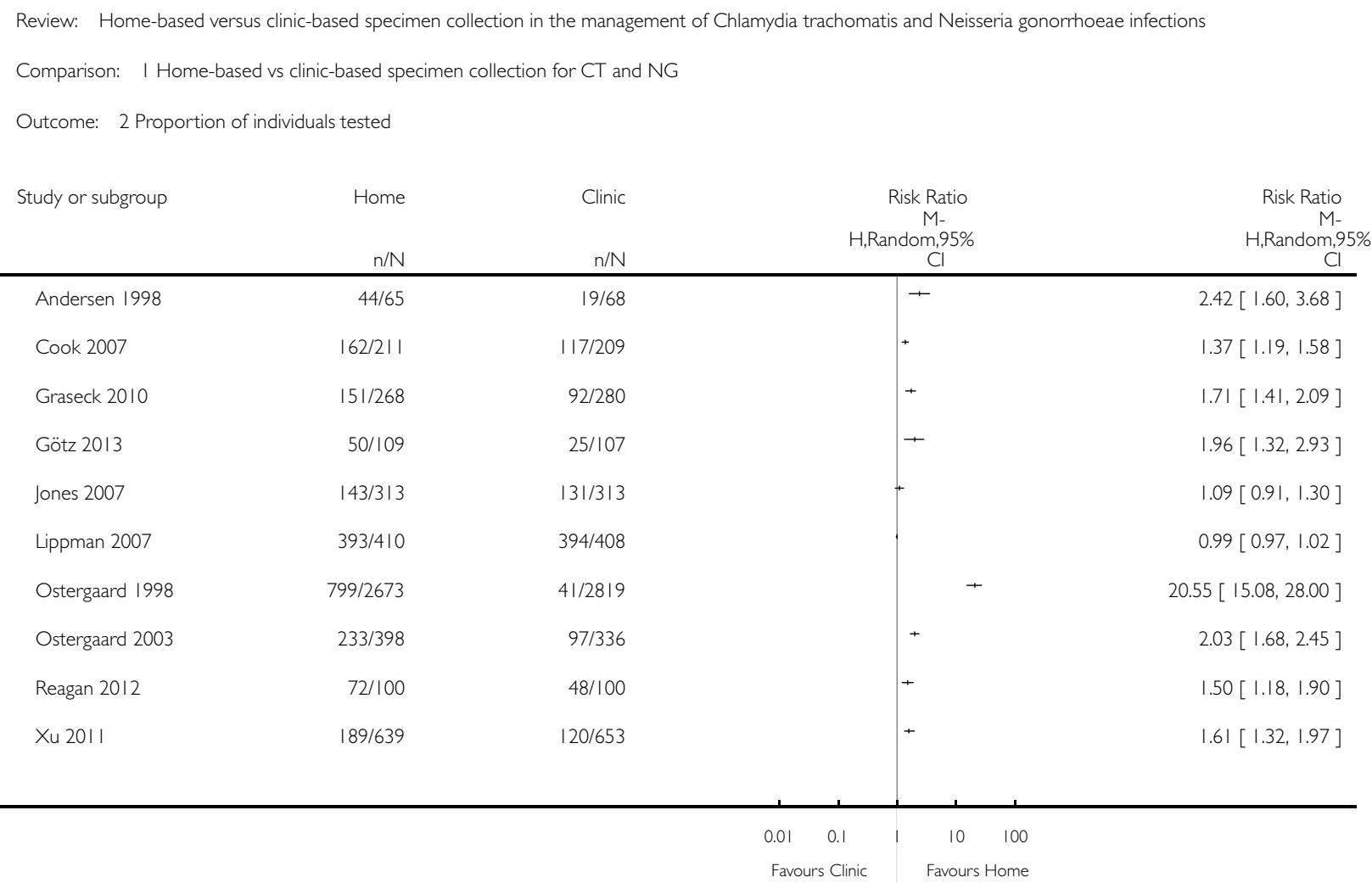


Analysis I.3. Comparison I Home-based vs clinic-based specimen collection for CT and NG, Outcome 3 Proportion of individual tested grouped by sex.

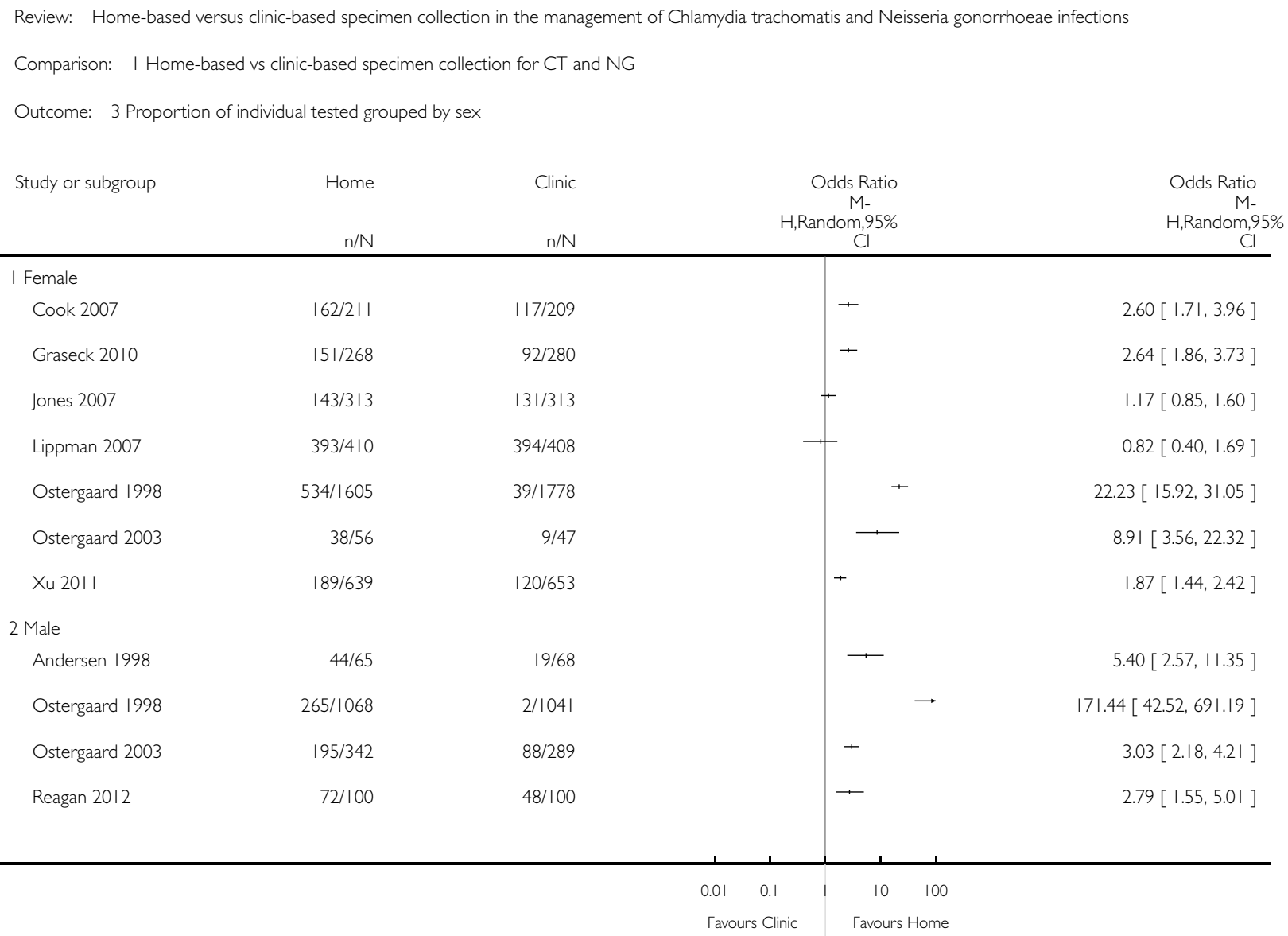


Analysis I.4. Comparison I Home-based vs clinic-based specimen collection for CT and NG, Outcome 4 Proportion of individual tested grouped by risk.

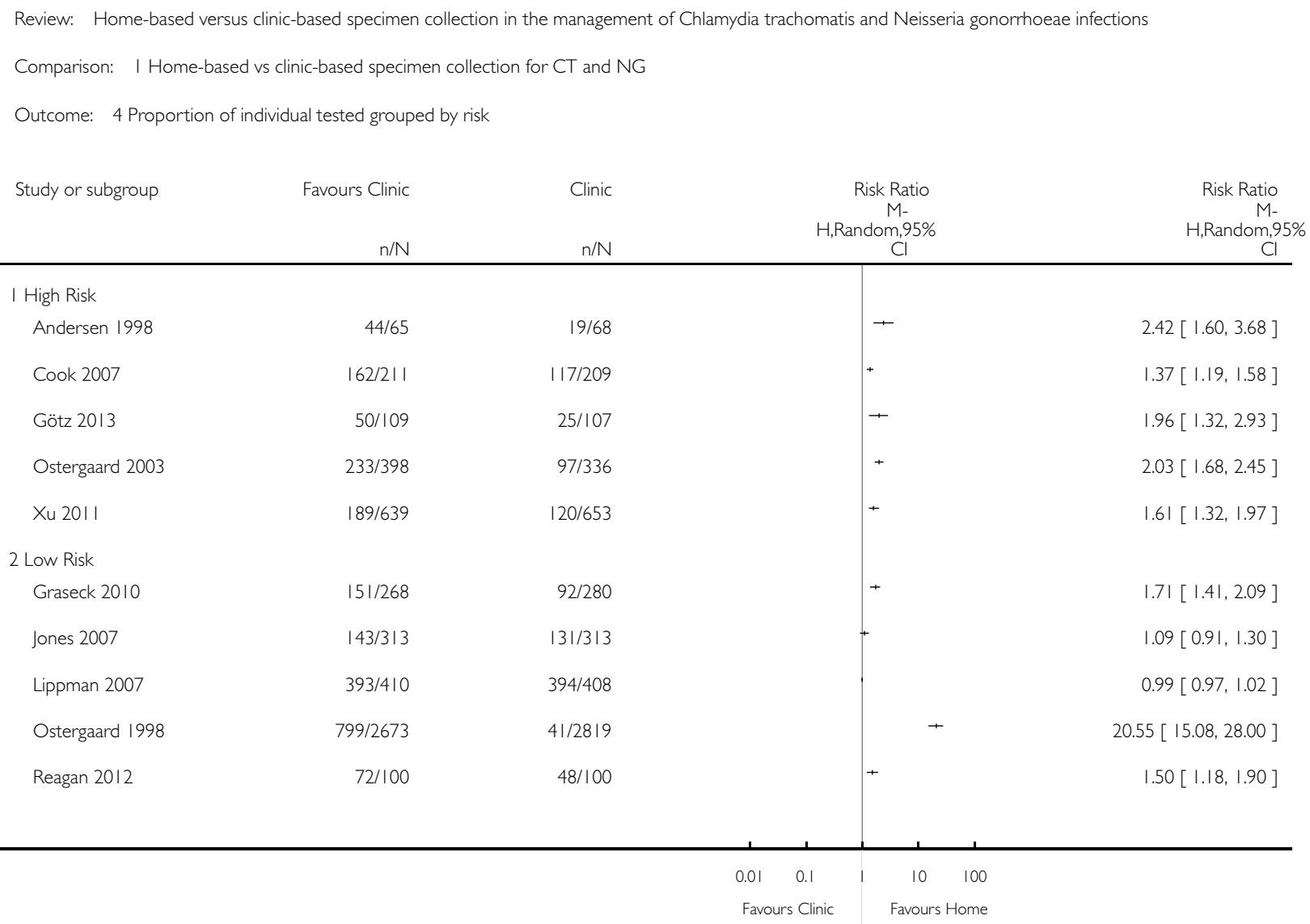


Analysis I.5. Comparison I Home-based vs clinic-based specimen collection for CT and NG, Outcome 5 Proportion of individual tested grouped by method of returning specimens.

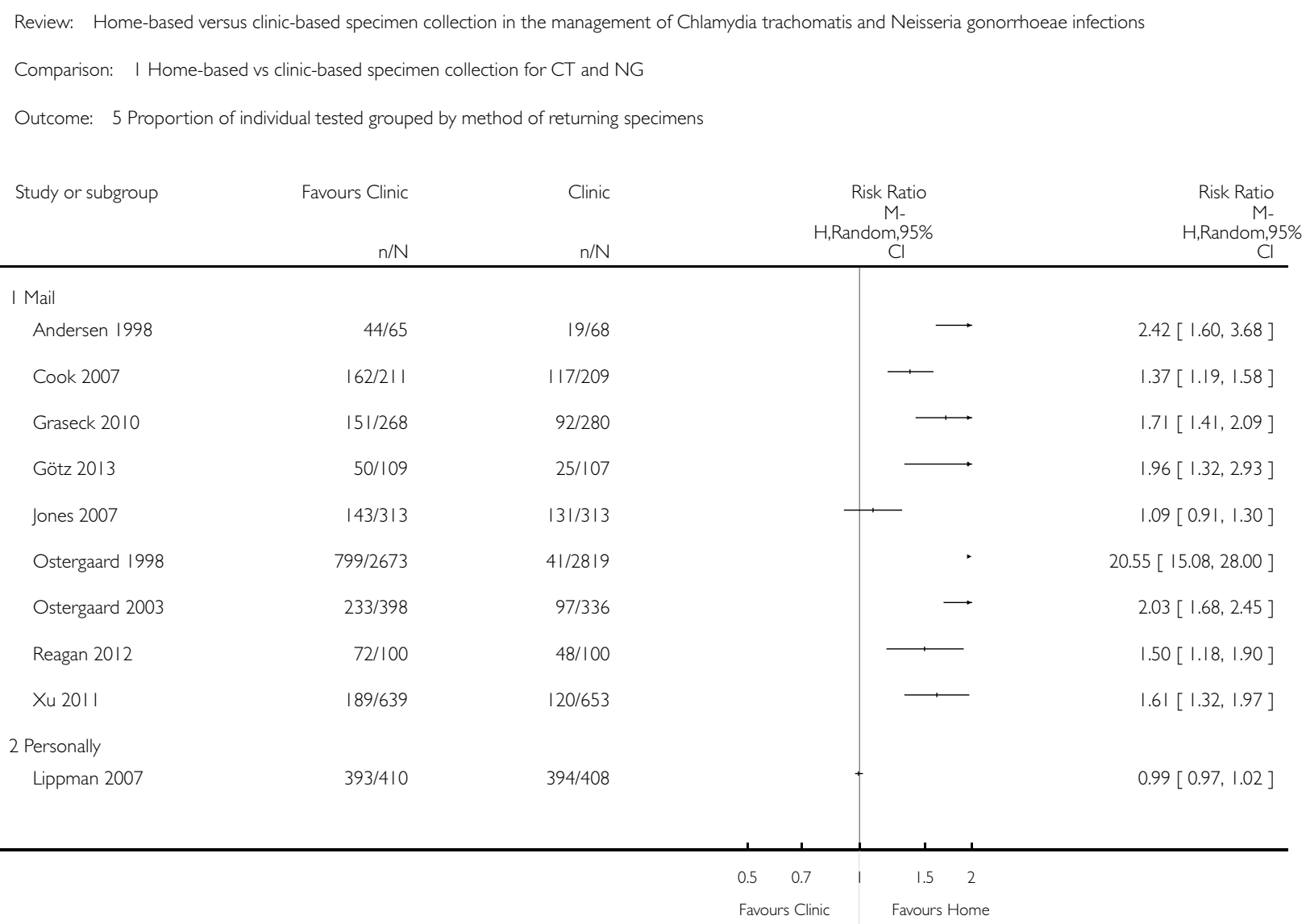


Analysis I.6. Comparison I Home-based vs clinic-based specimen collection for CT and NG, Outcome 6 Proportion of individual tested grouped by use of reminders.

Review: Home-based versus clinic-based specimen collection in the management of Chlamydia trachomatis and Neisseria gonorrhoeae infections

Comparison: I Home-based vs clinic-based specimen collection for CT and NG

Outcome: 6 Proportion of individual tested grouped by use of reminders

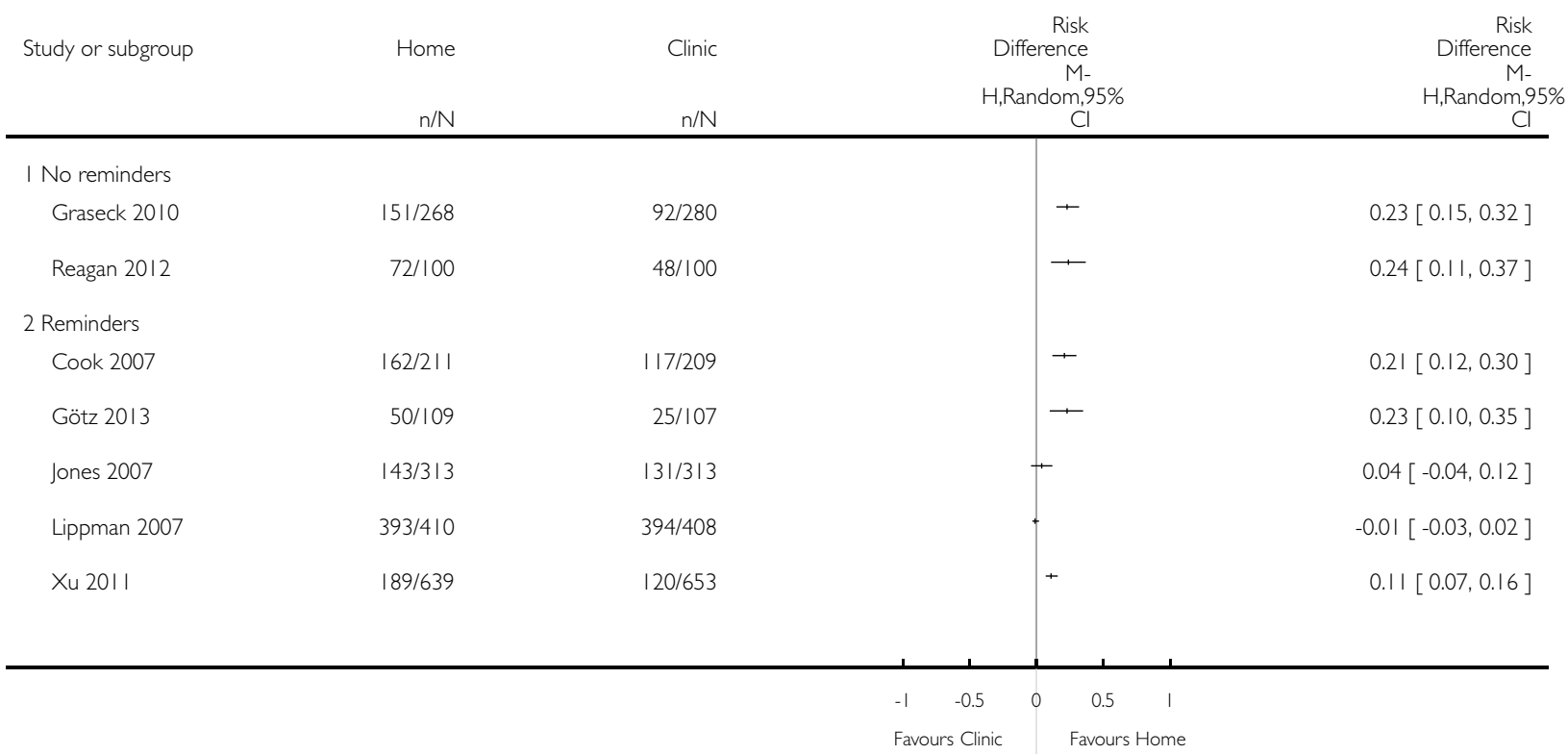




\section{Analysis I.7. Comparison I Home-based vs clinic-based specimen collection for CT and NG, Outcome 7 Positive test prevalence.}

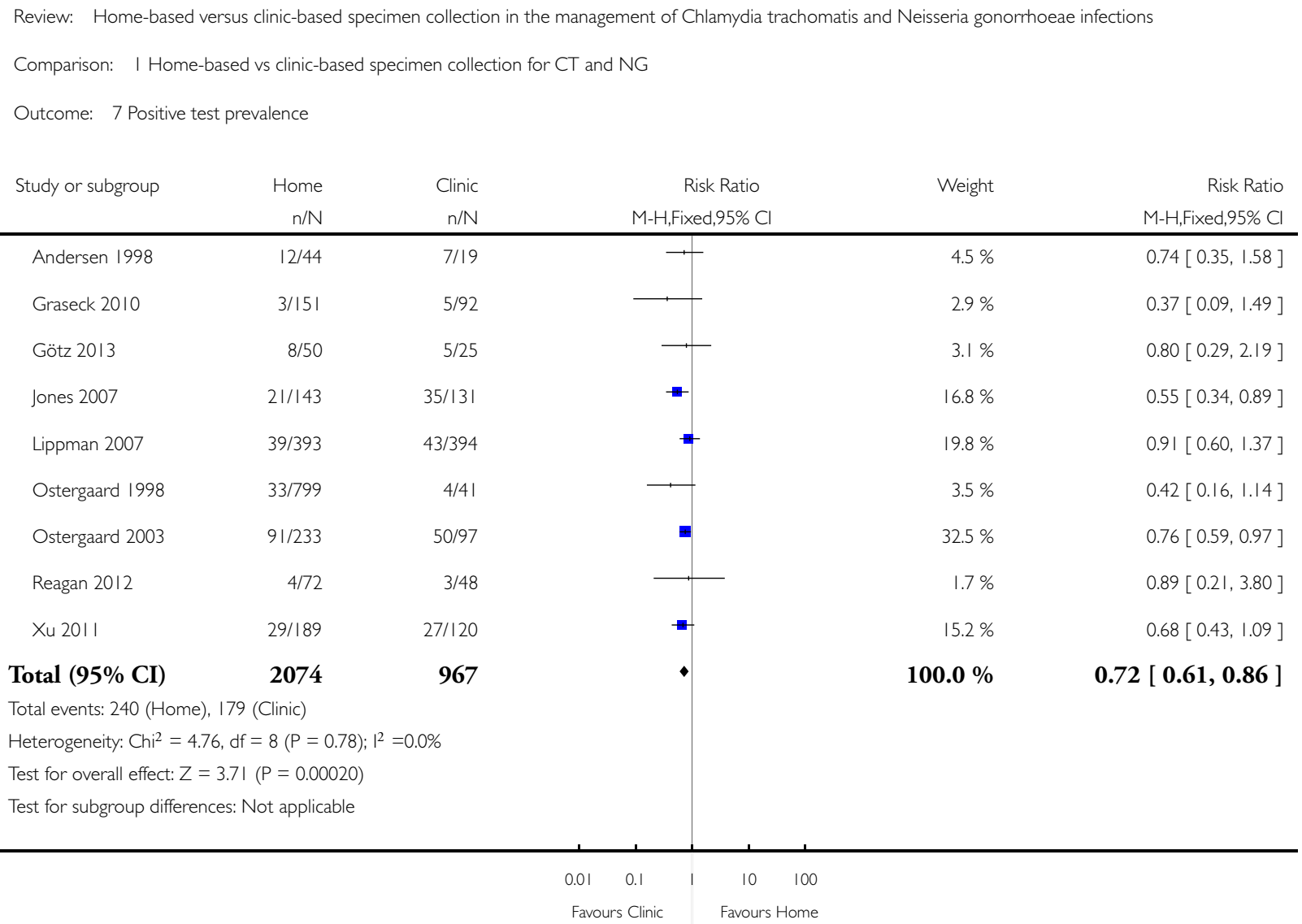

\section{ADDITIONAL TABLES}

Table 1. Strategy components for CT and NG detection

\begin{tabular}{l|ll}
\hline Component & Home-based strategy & Clinic-based strategy \\
\hline 1. Place of specimen collection & Home-based & Clinic-based \\
\hline 2. Process for specimen collection & Self-collected & Self-collected or physician collected \\
\hline 3. Specimen collection device & Could differ & Could differ \\
\hline 4. Specimen transport conditions & Possible mailing delays, ambient tempera- & $\begin{array}{l}\text { Should have fewer delays, may have cold } \\
\text { chain }\end{array}$
\end{tabular}


Table 1. Strategy components for CT and NG detection

\begin{tabular}{l|l|l} 
5. Specimen delivery & $\begin{array}{l}\text { Patient mails or delivers to laboratory or } \\
\text { clinic }\end{array}$ & No involvement for patient \\
\hline 6. Specimen processing & Same & Same \\
\hline 7. Accuracy of the diagnostic test & Same & Same \\
\hline 8. Process for notifying provider of results & Same & Could differ \\
\hline 9. Process for notifying patient of results & Could differ & Same \\
\hline $\begin{array}{l}\text { 10. Treatment } \\
\text { 11. Partner management and patient fol- } \\
\text { low-up }\end{array}$ & Same & Same \\
\hline
\end{tabular}

\section{A P PENDICES}

\section{Appendix I. Search strategies}

\section{MEDLINE and CENTRAL (Ovid platform)}

1 exp Chlamydia trachomatis/

2 (chlam?dia adj5 trachomatis).tw.

3 (chlamydozoon adj5 trachomatis)

4 (rickettsia adj5 trachoma\$).tw.

5 exp Chlamydia Infections/

6 (chlamydi?sis).tw.

7 (chlamydia\$ adj5 infection\$).tw.

8 exp Urethritis/

9 (chlamydia $\$$ adj5 urethritis).tw.

10 (urogenital adj5 chlamydia\$).tw.

11 exp Neisseria gonorrhoeae/

12 (neisseria adj5 gonorrhoeae).tw.

13 (gonococcus).tw.

14 (diplococcus adj5 neisser).tw.

15 exp Gonorrhea/

16 (gonococc\$ adj5 infection\$).tw.

17 (gonococcosis).tw.

18 (gonorrhoea).tw.

19 (gonorrh?eae).tw.

20 (gonorrhea $\$$ ).tw.

21 (gonococ\$ adj5 urethritis).tw.

22 (gonorrh $\$$ adj 5 urethritis).tw

Home-based versus clinic-based specimen collection in the management of Chlamydia trachomatis and Neisseria gonorrhoeae

Copyright $\odot 2015$ The Cochrane Collaboration. Published by John Wiley \& Sons, Ltd. 
23 (specific adj5 urethritis).tw.

24 or/ $1-23$

25 (home adj5 screen\$).tw.

26 (home adj5 collect\$).tw.

27 (home adj5 sampl\$).tw.

28 (home adj5 specimen\$).tw.

29 (home adj5 test\$).tw.

30 (home adj5 kit\$).tw.

31 (clinic\$ adj5 screen\$).tw.

32 (clinic\$ adj5 collect\$).tw.

33 (clinic\$ adj5 sampl\$).tw.

34 (clinic\$ adj5 specimen\$).tw.

35 (clinic\$ adj5 test\$).tw.

36 (physician adj5 collect\$).tw.

37 (medic\$ adj5 collect\$).tw.

38 exp Self-Examination/

39 (self adj5 collect $\$$ ).tw.

40 (self adj5 exam\$).tw.

41 (self adj5 sampl\$).tw.

42 (auto adj5 collect\$).tw.

43 (self adj5 test\$).tw.

44 (self adj5 specimen\$).tw.

45 (specimen\$ adj5 collect\$).tw.

46 (mail\$ adj5 collect\$).tw.

47 (mail\$ adj5 return\$).tw.

48 (screen $\$$ adj5 test $\$$ ).tw.

49 or/25-48

50 randomized controlled trial.pt.

51 controlled clinical trial.pt.

52 randomized.ab.

53 placebo.ab.

54 clinical trials as topic.sh.

55 randomly.ab.

56 trial.ti.

57 or/50-56

58 exp animals/ not humans.sh.

5957 not 58

6024 and 49 and 59

Note: the CENTRAL search strategy does not include the lines \#50 - \#59.

EMBASE (embase.com platform)

1 'Chlamydia trachomatis'/exp

2 (chlamidia NEAR/5 trachomatis):ab,ti

3 (chlamydia NEAR/5 trachomatis):ab,ti

4 (chlamydozoon NEAR/5 trachomatis):ab,ti

5 (rickettsia NEAR/5 trachoma*):ab,ti

6 'chlamydiasis'/exp

7 (chlamydiasis):ab,ti

8 (chlamydiosis):ab,ti

9 (chlamydia* NEAR/5 infection*):ab,ti

10 'chlamydial urethritis'/exp

11 (chlamydia* NEAR/5 urethritis):ab,ti

Home-based versus clinic-based specimen collection in the management of Chlamydia trachomatis and Neisseria gonorrhoeae

Copyright $\Subset 2015$ The Cochrane Collaboration. Published by John Wiley \& Sons, Ltd. 
12 (urogenital NEAR/5 chlamydia*):ab,ti

13 'Neisseria gonorrhoeae'/exp

14 (neisseria NEAR/5 gonorrhoeae):ab,ti

15 (gonococcus):ab,ti

16 (diplococcus NEAR/5 neisser):ab,ti

17 'gonorrhea'/exp

18 (gonococc* NEAR/5 infection*):ab,ti

19 (gonococcosis):ab,ti

20 (gonorrhoea):ab,ti

21 (gonorrhaeae):ab,ti

22 (gonorrhoeae):ab,ti

23 (gonorrhea*):ab,ti

24 'gonococcal urethritis'/exp

25 (gonococ* NEAR/5 urethritis):ab,ti

26 (gonorrh* NEAR/5 urethritis):ab,ti

27 (specific NEAR/5 urethritis):ab,ti

28 or/1-27

29 (home NEAR/5 screen*):ab,ti

30 (home NEAR/5 collect*):ab,ti

31 (home NEAR/5 sampl*):ab,ti

32 (home NEAR/5 specimen*):ab,ti

33 (home NEAR/5 test*):ab,ti

34 (home NEAR/5 kit*):ab,ti

35 (clinic* NEAR/5 screen*):ab,ti

36 (clinic* NEAR/5 collect*):ab,ti

37 (clinic* NEAR/5 sampl*):ab,ti

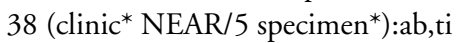

39 (clinic* NEAR/5 test*):ab,ti

40 (physician NEAR/5 collect*):ab,ti

41 (medic* NEAR/5 collect*):ab,ti

42 'self examination'/exp

43 (self NEAR/5 collect*):ab,ti

44 (self NEAR/5 exam*):ab,ti

45 (self NEAR/5 sampl*):ab,ti

46 (auto NEAR/5 collect*):ab,ti

47 (self NEAR/5 test ${ }^{*}$ ):ab,ti

48 (self NEAR/5 specimen*):ab,ti

49 (specimen* NEAR/5 collect*):ab,ti

50 (mail* NEAR/5 collect*):ab,ti

51 (mail* NEAR/5 return*):ab,ti

52 'screening test'/exp

53 (screen* NEAR/5 test ${ }^{*}$ ):ab,ti

54 or/29-53

55 'clinical trial'/exp

56 'randomized controlled trial'/exp

57 'randomization'/exp

58 'single blind procedure'/exp

59 'double blind procedure'/exp

60 'crossover procedure'/exp

61 'placebo'/exp

62 (randomised NEAR/2 controlled NEAR/2 trial ${ }^{*}$ ) :ab,ti

63 (randomized NEAR/2 controlled NEAR/2 trial*) :ab,ti

64 rct :ab,ti

Home-based versus clinic-based specimen collection in the management of Chlamydia trachomatis and Neisseria gonorrhoeae

Copyright $\odot 2015$ The Cochrane Collaboration. Published by John Wiley \& Sons, Ltd. 
65 (random NEAR/2 allocation) :ab,ti

66 (randomly NEAR/2 allocated) :ab,ti

67 (allocated NEAR/2 randomly) :ab,ti

68 (allocated NEAR/2 random) :ab,ti

69 (single NEAR/2 blind*) :ab,ti

70 (double NEAR/2 blind*) :ab,ti

71 (triple NEAR/2 blind *) :ab,ti

72 (placebo*) :ab,ti

73 'prospective study'/exp

74 or $/ 55-73$

75 'case study'/exp

76 case report :ab,ti

77 'abstract report'/exp

78 'letter'/exp

79 or/ $75-78$

8074 not 79

81 'animals'/exp

82 'invertebrate'/exp

83 'animal experiment'/exp

84 'animal model'/exp

85 'animal tissue'/exp

86 ' animal cell'/exp

87 'nonhuman'/exp

88 or/ $81-87$

88 'human'/exp

89 'normal human'/exp

90 'human cell'/exp

91 or/ $88-90$

9288 and 91

9388 not 92

9480 not 93

9528 and 54 and 94

Sexually Transmitted Infections Cochrane Review Group’s Specialized Register

Using the terms "Chlamydia trachomatis" OR “ Neisseria gonorrhoeae” AND "screen” in title, abstract and keywords.

\section{CONTRIBUTIONSOFAUTHORS}

1. Draft the protocol: LF, HG, EA, CR, NL

2. Study selection: PV, LF HG, JA

3. Extract data from studies: PV, LF, EA

4. Enter data into RevMan: LF

5. Carry out the analysis: CR, LF, EA

6. Interpret the analysis: LF, HG, EA, CR, NL

7. Draft the final review: LF, HG, EA, CR, NL

8. Disagreement resolution: $\mathrm{HG}$

Home-based versus clinic-based specimen collection in the management of Chlamydia trachomatis and Neisseria gonorrhoeae 
9. Update the review: LF, HG, EA, CR

\section{DECLARATIONSOF INTEREST}

None known

\section{SOURCES OF SUPPORT}

\section{Internal sources}

- No sources of support supplied

\section{External sources}

- Anne Anderson Award 2013, USA.

This review was supported by the Anne Anderson Award, its goal is to recognize and stimulate individuals contributing to the enhancement of women's visibility and participation in the Cochrane leadership, 2013 Recipient was Professor Cindy Farquhar and Designee Luisa Fajardo Bernal.

\section{DIFFERENCES BETWEEN PROTOCOLANDREVIEW}

We changed the name of the primary outcome to "index case management", rather than "complete case management".

We failed to implement some methods planned in our protocol, including analysis of measures of effect for continuous outcomes, and the unit of analysis issue for studies with multiple treatment groups, because of a lack of pertinent data. These methods may be relevant for future updates. We included one subgroup analysis that we did not state in the protocol: for the secondary outcome "proportion of individuals tested", we examined the findings according to the use of reminders. For the subgroup analyses to assess heterogeneity in random-effects models, we used meta-regression to estimate the ratio of risk ratios (RRR, with 95\% CI).

The 'Summary of findings' table was restricted to four outcomes: index case management, proportion of individuals tested, positive test prevalence, and adverse effects of testing. We added the secondary outcome "proportion of individuals tested" that was not prespecified in the protocol. We did not include the outcomes of infection cured, barriers to testing and costs because we did not find RCTs that evaluated these outcomes.

Patrick Vigil has been added as an author since the protocol was published. 